\title{
Review of the genus Chinoperla Zwick, 1980 (Plecoptera: Perlidae: Perlinae) from China
}

\author{
Rao-Rao MO ${ }^{\circledR 1}$, Rui-Jun LIU ${ }^{\circledR 2}$, Guo-Quan WANG ${ }^{\circledR 3, *}$, \\ Wei-Hai LI ${ }^{\circledR 4, *} \&$ Dávid MURÁNYI ${ }^{\circledR 5}$ \\ ${ }^{1,3}$ Guangxi key laboratory of Agric-Environment and Agric-Products Safety and \\ National Demonstration Center for Experimental Plant Science Education, \\ Agricultural College, Guangxi University, Nanning, Guangxi 530004, China. \\ ${ }^{2}$ Henan Institute of Science and Technology Herbarium, Xinxiang, Henan 453003, China. \\ ${ }^{1,4}$ Department of Plant Protection, Henan Institute of Science and Technology, \\ Xinxiang, Henan 453003, China. \\ ${ }^{5}$ Department of Zoology, Eszterházy Károly University, Leányka u. 6, Eger H-3300, Hungary. \\ *Corresponding authors: wangguoquan0@163.com (GQW); 1wh7969@163.com (WHL) \\ 1Email: 1689832746@qq.com \\ ${ }^{2}$ Email: histlruijun@163.com \\ 55mail: d.muranyi@gmail.com

\footnotetext{
${ }^{1}$ urn:Isid:zoobank.org:author:9F30237C-B493-4A90-A545-EDB2EDF11BF2

${ }^{2}$ urn:Isid:zoobank.org:author:1C00450A-AAE4-4F41-8E9D-11FB7A1E05FE

${ }^{3}$ urn:1sid:zoobank.org:author:2FAFA732-C8F7-4823-949A-EF81D6B6A2F4

${ }^{4}$ urn:1sid:zoobank.org:author:81D57DE5-E00B-4F6B-A0B3-E81D3C865208

${ }^{5}$ urn:lsid:zoobank.org:author:86C43175-8A78-44EB-A505-19553C6246CA
}

\begin{abstract}
The Chinese species of the genus Chinoperla Zwick, 1980 are reviewed. One species from Hainan is described as new to science: C. changjiangensis sp. nov. Chinoperla gorohovi Sivec \& Stark, 2010 is reported from China for the first time, with a redescripion and color images of the male, and the first description of the female and egg. Chinoperla nigrifrons (Banks, 1939) is redescribed and illustrated, synonymy of C. furcomacula (Wu, 1973) is confirmed. Taxonomic relationships within the studied species are discussed. A provisional key to the six known species of Chinoperla for China is presented.
\end{abstract}

Keywords. China, Chinoperla changjiangensis sp. nov., C. gorohovi Sivec \& Stark, 2010, synonymy, taxonomy.

Mo R.R., Liu R.J., Wang G.Q., Li W.H. \& Murányi D. 2021. Review of the genus Chinoperla Zwick, 1980 (Plecoptera: Perlidae: Perlinae) from China. European Journal of Taxonomy 775: 62-85.

https://doi.org/10.5852/ejt.2021.775.1547

\section{Introduction}

The genus Sinoperla Wu, 1948 was proposed based on one species: S. nigroflavata Wu, 1948 from Fujian Province of southeastern China. However, Chinoperla Zwick, 1980 had to be proposed to replace Sinoperla which was preoccupied by a fossil genus of stoneflies (Zwick 1980). Sinoperla furcomacula 
Wu, 1973, S. nigroflavata, Neoperla nigriceps Banks, 1914, N. fascipennis Banks, 1931 and N. reducta Geijskes, 1952 were transferred to the genus (Zwick 1980, 1982). Later on, Chinoperla nigrifrons (Banks, 1939) was also added to the genus, transfered from Ochthopetina Enderlein, 1909, a synonym of Neoperla Needham, 1905 (Sivec et al. 1988). The aedeagus of C. nigroflavata, the type species of the genus, was not everted and described in the original description, and it remained poorly known. Chinoperla furcomacula has been regarded as a synonym of $C$. nigrifrons by Sivec et al. (1988), while Sivec \& Zwick (1989) raised questions about their synonymy due to the different female genitalia. Both species have been described or briefly commented on in several studies, but their aedeagus still has not been fully described (Wu 1948, 1973; Zwick 1980, 1982; Sivec et al. 1988; Sivec \& Zwick 1989). Chinoperla currently contains 15 known species, restricted to Southern Asia (Yang \& Li 2018; DeWalt et al. 2021). Two Chinese species, C. biprojecta Lü, Yan, Li \& Wang, 2019 and C. mengmanensis Qian \& Du, 2012, were recently described from Hainan and Yunnan, respectively. Therefore, up to now, there are four species of Chinoperla known from China.

In the present paper, we present a review of six species of Chinoperla from China. A redescription and detailed comments on $C$. nigrifrons are provided. We support the fact that that holotype C. furcomacula is conspecific with C. nigrifrons. Chinoperla changjiangensis sp. nov. is described from both sexes and eggs, collected in the Bawangling National Nature Reserve of Hainan Province. The male paratype of $C$. nigrifrons is proved to be distinct from the holotype, and belongs to $C$. changjiangensis sp. nov. Chinoperla gorohovi Sivec \& Stark, 2010 from Mountain Nankunshan of Guangdong Province is newly reported from China with a redescription of the male, while the female and egg are described for the first time. A provisional key to the presently known Chinese species of the genus is also given.

\section{Material and methods}

Studied specimens are deposited in the Entomological Museum of China Agricultural University, Beijing (CAU), the Henan Institute of Science and Technology, Xinxiang (HIST), Henan Province, the National Zoological Museum of China, Institute of Zoology, Chinese Academy of Sciences, Beijing (IZCAS) and the Museum of Comparative Zoology, Harvard University, Cambridge, Massachusetts (MCZ), respectively, as indicated in the text. New specimens were collected using sweep nets or by hand, and stored in $75 \%$ ethanol. Color illustrations were made with the aid of an Imaging Source CCD attached to a Leica M420 microscope in the HIST, further color illustrations were made with a Leica C camera via the lens of an Olympus SZX7 microscope in the IZCAS. At the MCZ, the color illustrations were made with a Leica $\mathrm{C}$ camera via the lens of a Wild Photomakroskop M400. Further line drawings were made by free hand. All pictures were adjusted and assembled into plates with Adobe Photoshop CC 2019. Abdomens of the specimens were cleared in $10 \% \mathrm{NaOH}$. The morphological terminology follows that of Lü et al. (2019a) and Sivec \& Zwick (1989).

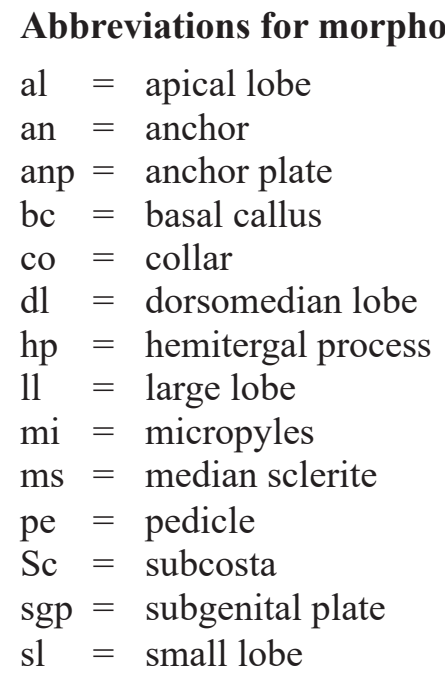




\title{
Results
}

Taxonomy

\author{
Class Insecta Linnaeus, 1758 \\ Order Plecoptera Burmeister, 1839 \\ Family Perlidae Latreille, 1802 \\ Genus Chinoperla Zwick, 1980
}

Sinoperla Wu, 1948: 78. Type species: S. nigroflavata Wu, 1948.

Chinoperla Zwick, 1980: 6. Inherited type species: S. nigroflavata Wu, 1948.

Chinoperla -Zwick \& Sivec 1980: 130. —Zwick 1982: 167. - Sivec et al. 1988: 54. —Sivec \& Zwick 1989: 11. - Du et al. 1999: 62. — Cao \& Bae 2007: 125. — Sivec \& Stark 2010: 62. — Chen \& Du 2018: 64. — Yang \& Li 2018: 36.

\section{Diagnosis}

Biocellate. Body relatively small. General color brown to dark brown. Macropterous; Sc vein of forewing usually short, ending in basal third. Head mostly pale brown to brown, often covered by a darker spot, and with mesal occipital knob. Male abdominal sterna 3-4, sometimes 5, with hair brushes. Tergum 9 with a slender, bilobed mesal sclerite. Hemitergal processes slender, approaching posterior mesal sclerite of tergum 9, and with basal callus covered by sensilla basiconica. Aedeagal tube partially sclerotized dorsally. Aedeagal sac subequal in length to tube, ventral portion usually with a basal patch of spinules, apically with short to long spines.

Chinoperla biprojecta Lü, Yan, Li \& Wang, 2019

Chinoperla biprojecta Lü et al., 2019a: 187, figs 1-2 (original description of the male).

Chinoperla biprojecta - Lü et al. 2019b: 600 (erratum).

\section{Material examined}

CHINA • 1 गे; Hainan Province, Changjiang County, Bawangling National Forest Park; $19^{\circ} 15^{\prime} 1.44^{\prime \prime}$ N, $109^{\circ} 2^{\prime} 2.4^{\prime \prime}$ E; alt. 1000 m; 9-10 Jun. 2007; Jie Zeng leg.; HIST.

\section{Distribution}

China: Hainan Province, Ledong and Changjiang Counties.

\section{Remarks}

This species is characterized by the median sclerite of tergum 9 forming an inverted triangle bearing two finger-shaped posterolateral projections. The aedeagus of the present specimen agrees well with the type material.

Chinoperla changjiangensis sp. nov. urn:1sid:zoobank.org:act:2535AC4B-4844-43E7-95EC-F9F9F0793C33

Figs $1-5$

Ochthopetina nigrifrons - Banks 1939: 449 (partim; a male paratype of C. nigrifrons).

Chinoperla nigrifrons - Sivec \& Zwick 1989: 14, fig. 3 b (partim; a male paratype of C. nigrifrons). 


\section{Diagnosis}

Head with a dark brown central spot subdivided by the lighter M-line. Male tergum 9 with a trumpet-shaped median sclerite. Aedeagal tube with a T-shaped sclerotized dorsal marking. Aedeagal sac dorsoapically with a low membranous median lobe and fringed with several small spines at its margin; ventrally with a rectangular sclerite armed with three to five spines arranged in a comb-shape; ventrolaterally with two subapical groups of small spines; apically with a long straight spine and a large spinose lobe; laterally with six large curved spines on each side. Posterior margin of female sternum 8 slightly produced, forming a triangular subgenital plate with a shallow mesal notch. Eggs brown, oval shaped with small collar.

\section{Etymology}

The name refers to the type locality, Changjiang Li Autonomous County.

\section{Material examined}

Holotype

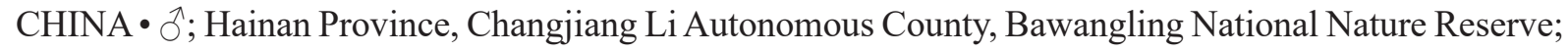
$19^{\circ} 15^{\prime} 1.440^{\prime \prime} \mathrm{N}, 109^{\circ} 2^{\prime} 2.4^{\prime \prime}$ E; alt. 1000 m; 9-10 Jun. 2007; Jie Zeng leg.; CAU.

\section{Paratypes}

CHINA $\bullet 1$ + ; same collection data as for holotype; CAU $\bullet 1$ त; same collection data as for holotype; HIST.

\section{Other material}

CHINA 1 ô (paratype of C. nigrifrons); "Hainan, Ta Han" [Hainan Province, Qiongzhong Li and Miao Autonomous County, located in Limushan Town]; 23 Jun.1935; L. Gressitt leg.; MCZ.

\section{Description}

\section{Male}

Adult Habitus (Figs 1A, 3A-C). General color pale brown. Forewing length 6.8-7.0 mm, hindwing length 6.1-6.2 mm. Head pale brown, with a dark brown central spot subdivided by the lighter M-line; biocellate, ocelli about 3 diameters apart of each other but still closer to each other than to the compound eye; antennae brownish. Pronotum pale brown, trapezoidal, with obscure paler rugosities and darker midline; anterior corners pointed but posterior corners obtuse. Legs pale brown, joints darker; wings subhyaline and yellowish brown, veins brown, Sc of forewing short, typical of the genus; cerci pale.

Aвdomen (Figs 1B-D, 3D-E). Sterna 3-5 with hair brushes. Dark median sclerite of tergum 9 trumpetshaped, about half as long as the segment, heavily sclerotized, distally forked with two blunt points. Hemitergal processes slender, about $2.5 \times$ as long as basal width; triangular in lateral view; basal callus fully covered with sensilla basiconica.

Aedeagus (Figs 2, 3F). Aedeagal tube dorsally sclerotized, sclerite forming a T-shaped marking. Sac as long as the tube when fully everted, distinctly curved dorsad; dorsoapical surface with a low membranous median lobe and several small spines located in a fringe; a single large straight spine about as long as $1 / 3$ aedeagus length and a large spinose lobe medially at apex, directed dorsally; ventral surface with a large basal patch of spinules, and a rectangular sclerite armed with three to five spines arranged in a combshape; two subapical groups of small spines located in ventrolateral surface; lateroapical part with six large curved spines on each side.

\section{Female}

Adult Habitus (Fig. 4A). Forewing length ca $8.0 \mathrm{~mm}$, hindwing length ca $7.0 \mathrm{~mm}$. Habitus generally similar to male. 
Aвdomen (Fig. 4B). Subgenital plate of sternum 8 slightly produced, triangular, bearing a small semicircular mesal notch.

EGG (Figs 4C-D, 5). Length 272-280 $\mu \mathrm{m}$, width 214-218 $\mu \mathrm{m}(\mathrm{N}=5)$. Several mature eggs were dissected from female terminalia. Oval-shaped with obscure opercular line, widest in subequatorial area towards opercular end. Anchor absent from the studied eggs. Collar short and button-shaped. Chorionic surface brown with heavy and distinct punctuations throughout. Micropylar orifices sessile, much larger than punctuations, set on subequatorial line.

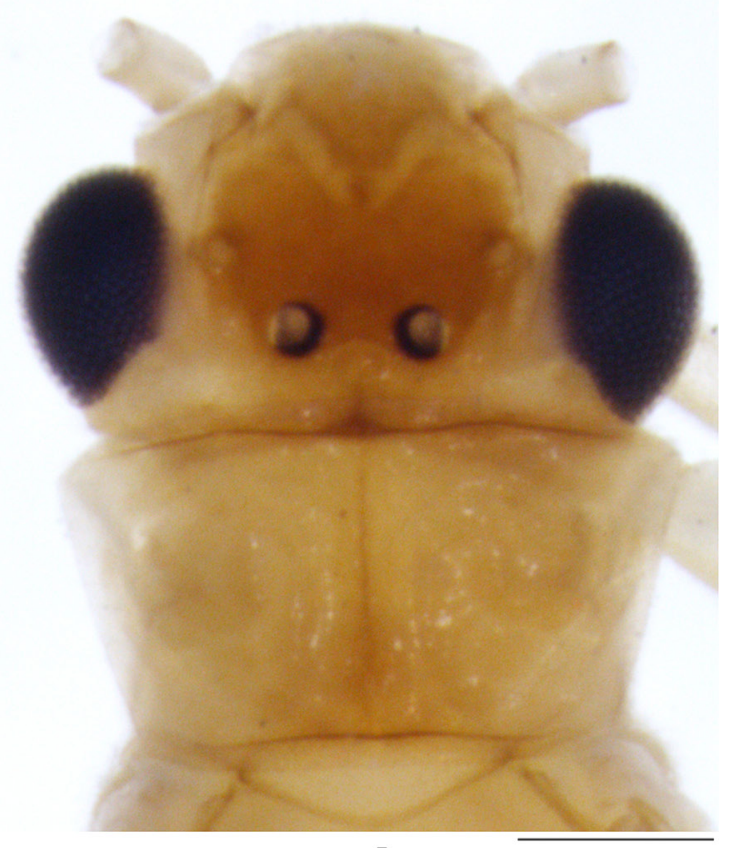

A

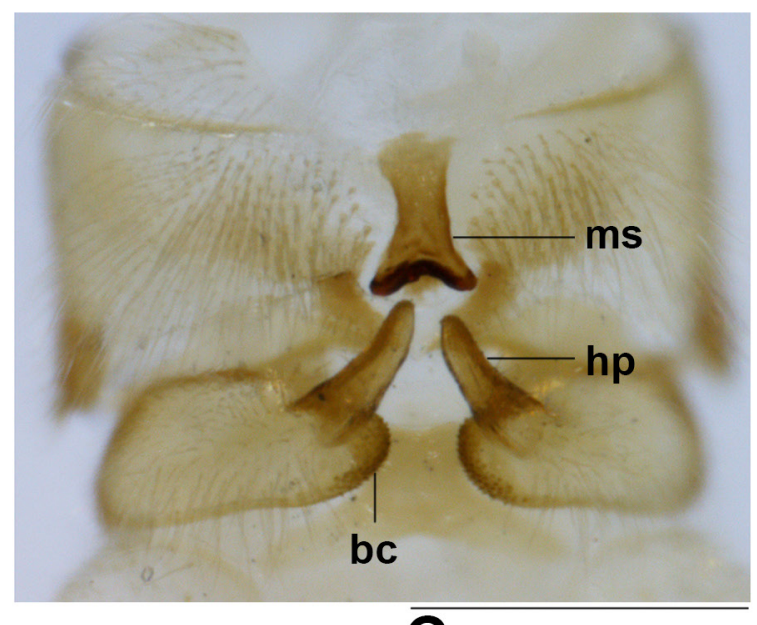

$\mathbf{C}$

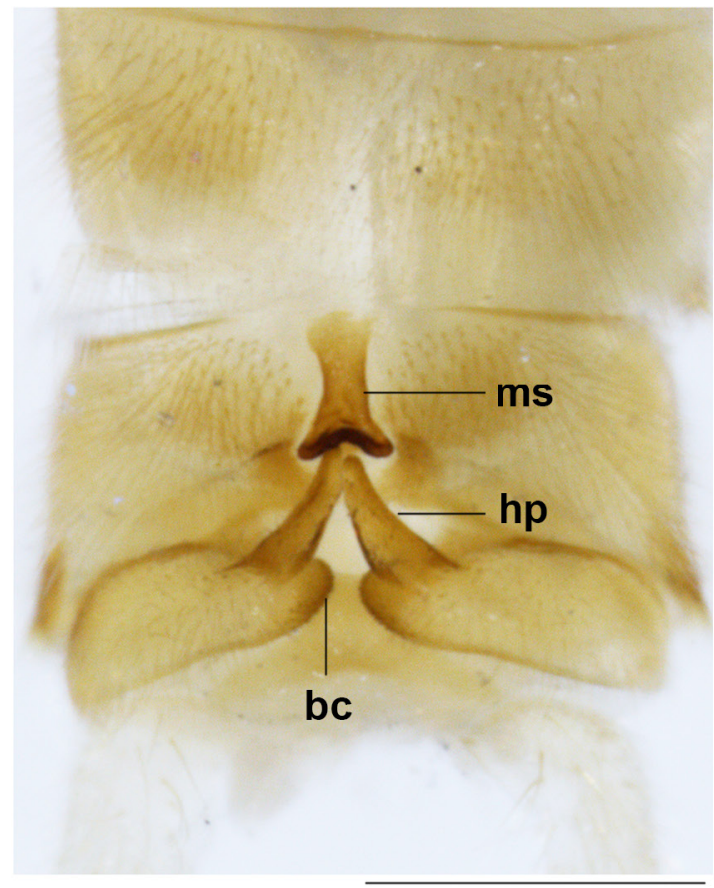

B

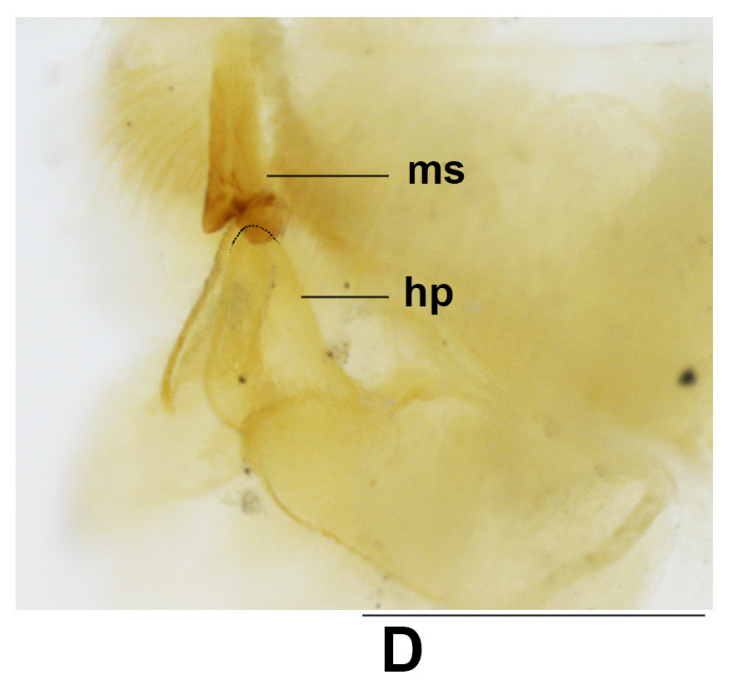

Fig. 1. Chinoperla changjiangensis sp. nov., $\hat{\jmath}$, paratype (HIST). A. Head and pronotum, dorsal view. B. Terminalia, dorsal view. C. Cleared terminalia, dorsal view. D. Cleared terminalia, lateral view. Abbreviations: see Material and methods. Scale bars $=0.5 \mathrm{~mm}$. 

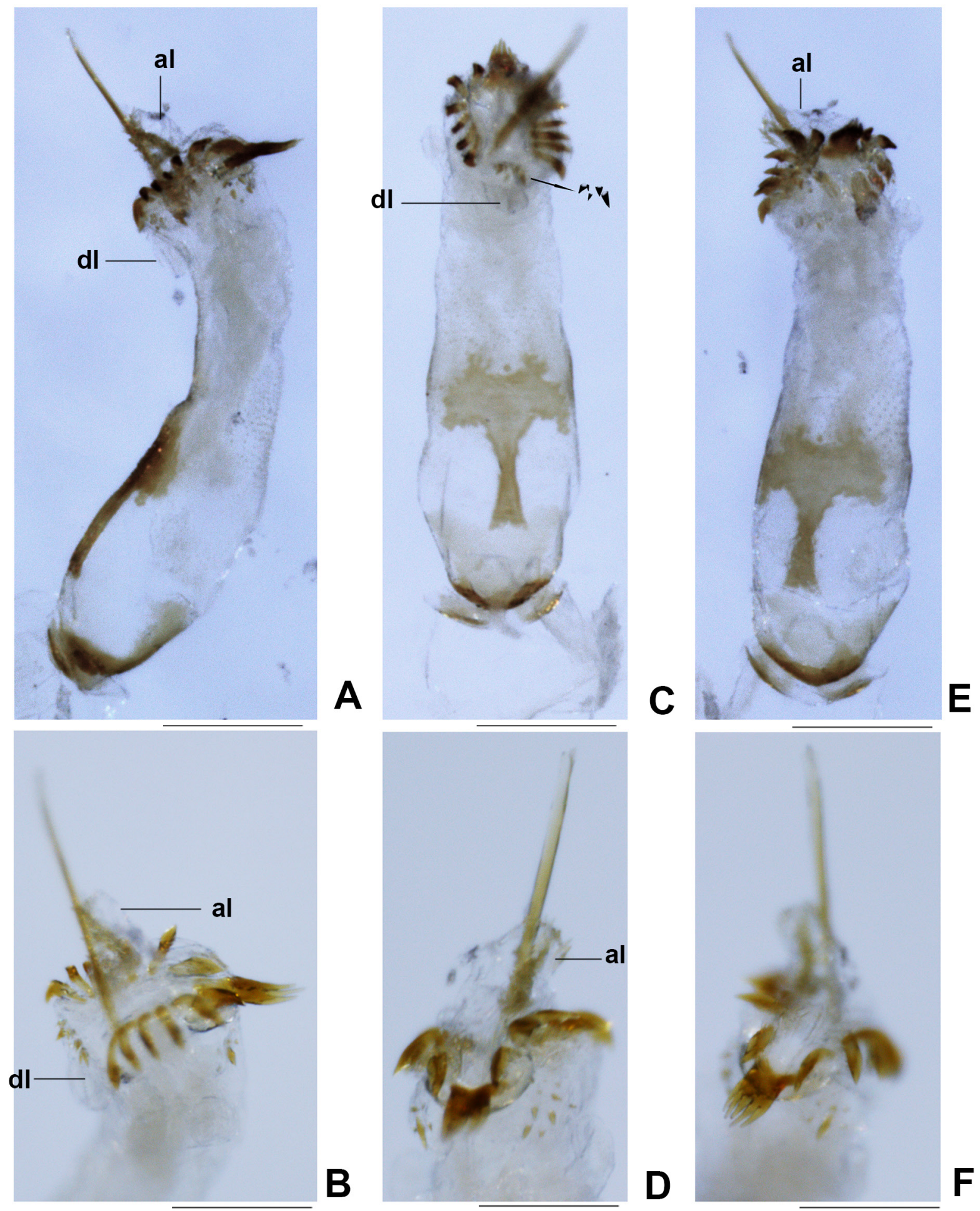

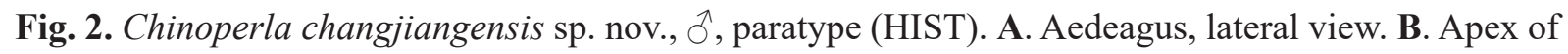
aedeagal sac, lateral view. C. Aedeagus, dorsal view (diagram of dorsoapical spines indicated by arrow). D. Apex of aedeagal sac, ventral view. E. Aedeagus, ventral view. F. Apex of aedeagal sac, oblique ventral view. Abbreviations: see Material and methods. Scale bars $=0.25 \mathrm{~mm}$. 


\section{Distribution}

China: Hainan Province. Known only from the type locality.

\section{Remarks}

One of the male paratypes of $C$. nigrifrons (Banks, 1939) belongs to C. changjiangensis sp. nov. The aedeagal tube of this male had been damaged before our examination. After further gentle squeezing, the sac was nearly fully everted but quite distorted; the observable armatures are illustrated on Fig. 3F. Since the aedeagus is partly damaged, we are not sure whether additional spines remained hidden and were not disclosed in the present study, hence the specimen is not designed as a paratype of $C$. changjiangensis sp. nov.
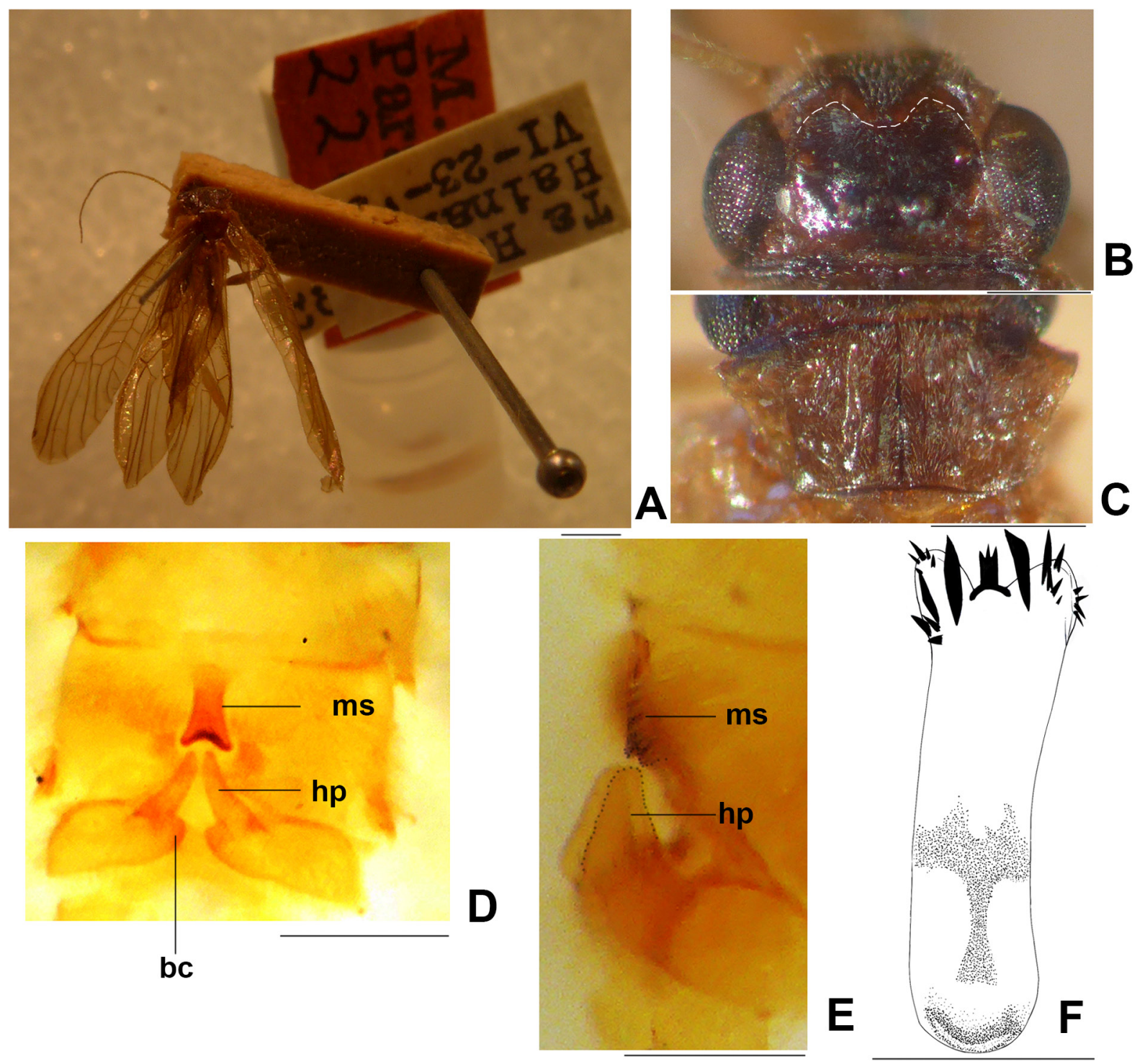

Fig. 3. Chinoperla changjiangensis sp. nov., Ô, paratype of C. nigrifrons (Banks, 1939) (MCZ). A. Adult habitus, dorsal view. B. Head, dorsal view. C. Pronotum, dorsal view. D. Cleared terminalia, dorsal view. E. Cleared terminalia, lateral view. F. Aedeagus, dorsal view. Abbreviations: see Material and methods. Scale bars: $\mathrm{A}=1.0 \mathrm{~mm}$; $\mathrm{B}-\mathrm{F}=0.5 \mathrm{~mm}$. 
The new species and C. biprojecta Lü, Yan, Li \& Wang, 2019 are most similar in head pattern, hemitergal processes, aedeagal tube, and aedeagal sac that is apically armed with a long spine, a large lobe and a comb-shaped sclerite. However, $C$. changjiangensis sp. nov. is easily distinguishable from the latter by the trumpet-shaped median sclerite of tergum 9 and the comb-shaped sclerite of the aedeagal sac with five short spines arising from the rectangular sclerite. In C. biprojecta, the median sclerite of tergum 9 is triangular with two finger-shaped projections bearing several black tiny warts, and the comb-shaped sclerite has four longer spines extending from the triangular basal sclerite. The apical portion of the aedeagal sac of the new species has six curved lateral spines on each side and three groups of short spines, while in C. biprojecta the lateroapical spines of the aedeagus are longer and hook-like, without more

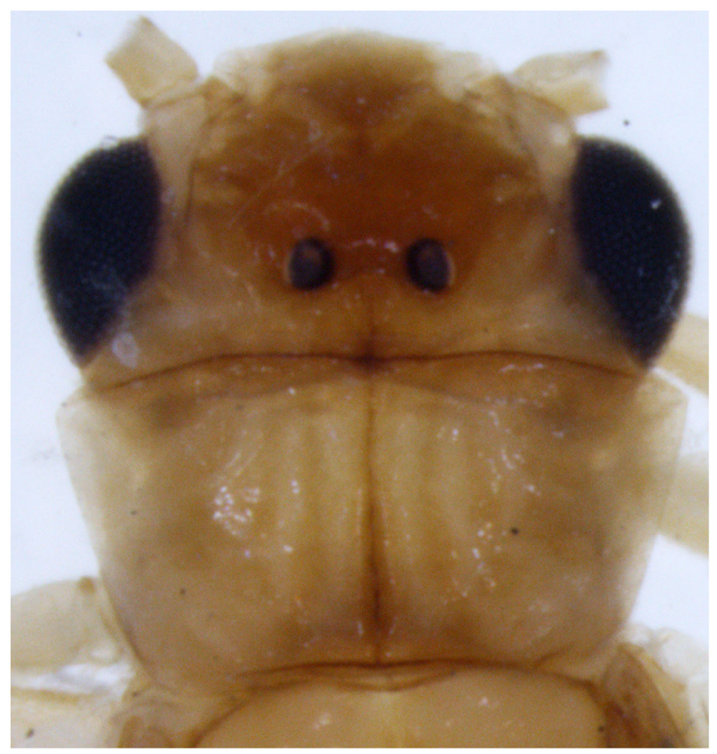

A

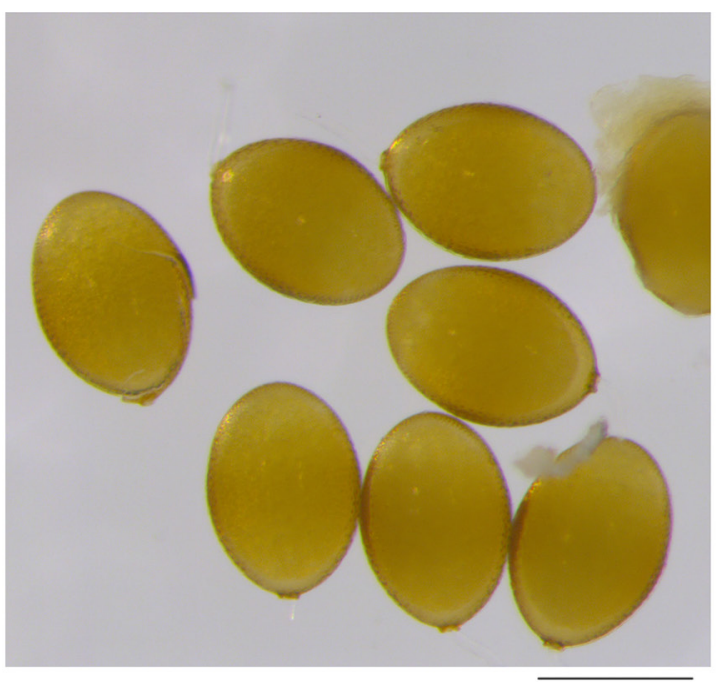

C

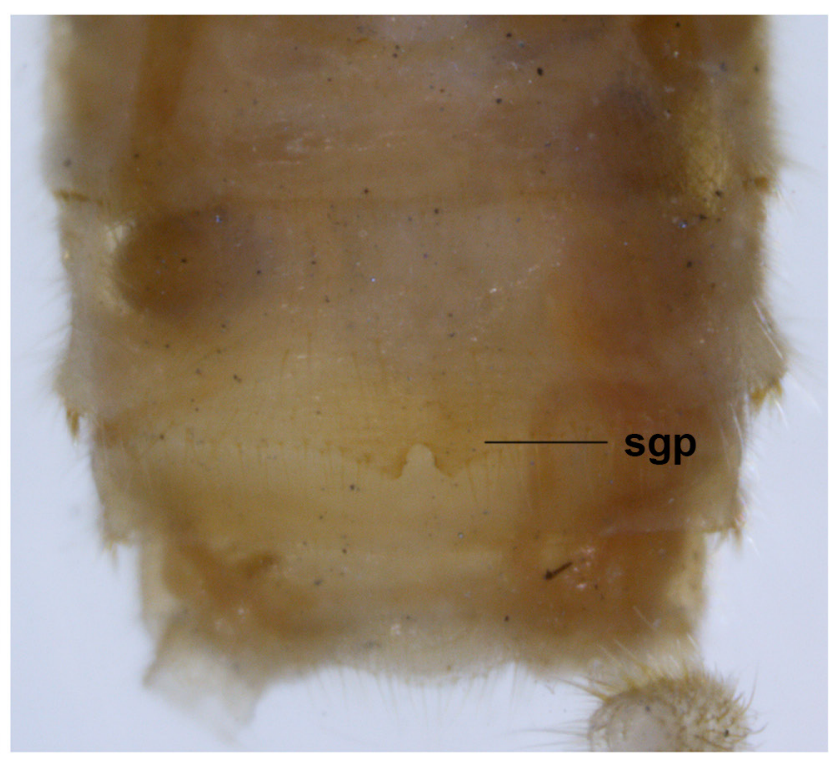

B

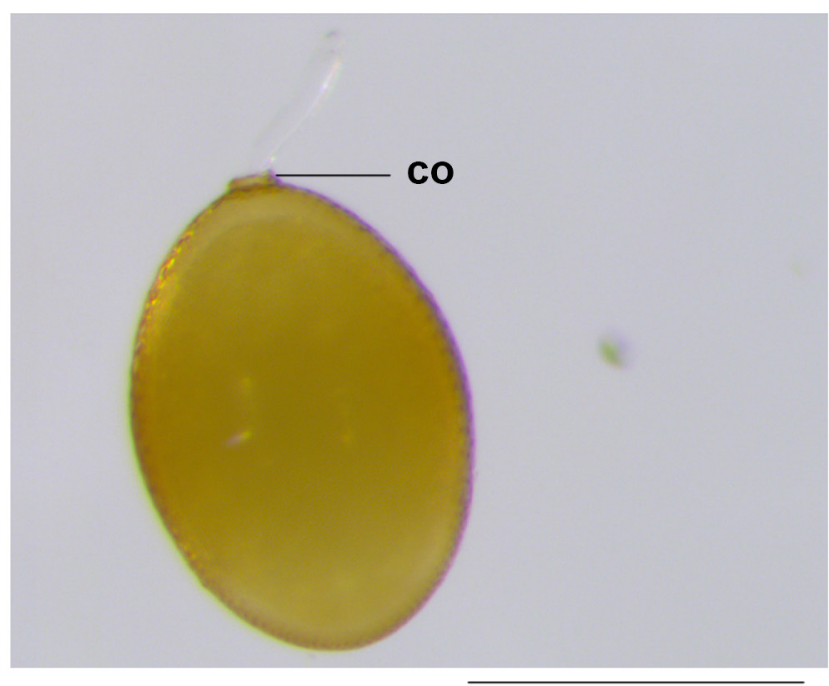

D

Fig. 4. Chinoperla changjiangensis sp. nov., + , paratype (CAU) A. Head and pronotum, dorsal view. B. Terminalia, ventral view. C. Eggs, lateral view. D. Entire egg, lateral view. Abbreviations: see Material and methods. Scale bars: A-B $=0.5 \mathrm{~mm} ; \mathrm{C}-\mathrm{D}=0.2 \mathrm{~mm}$. 

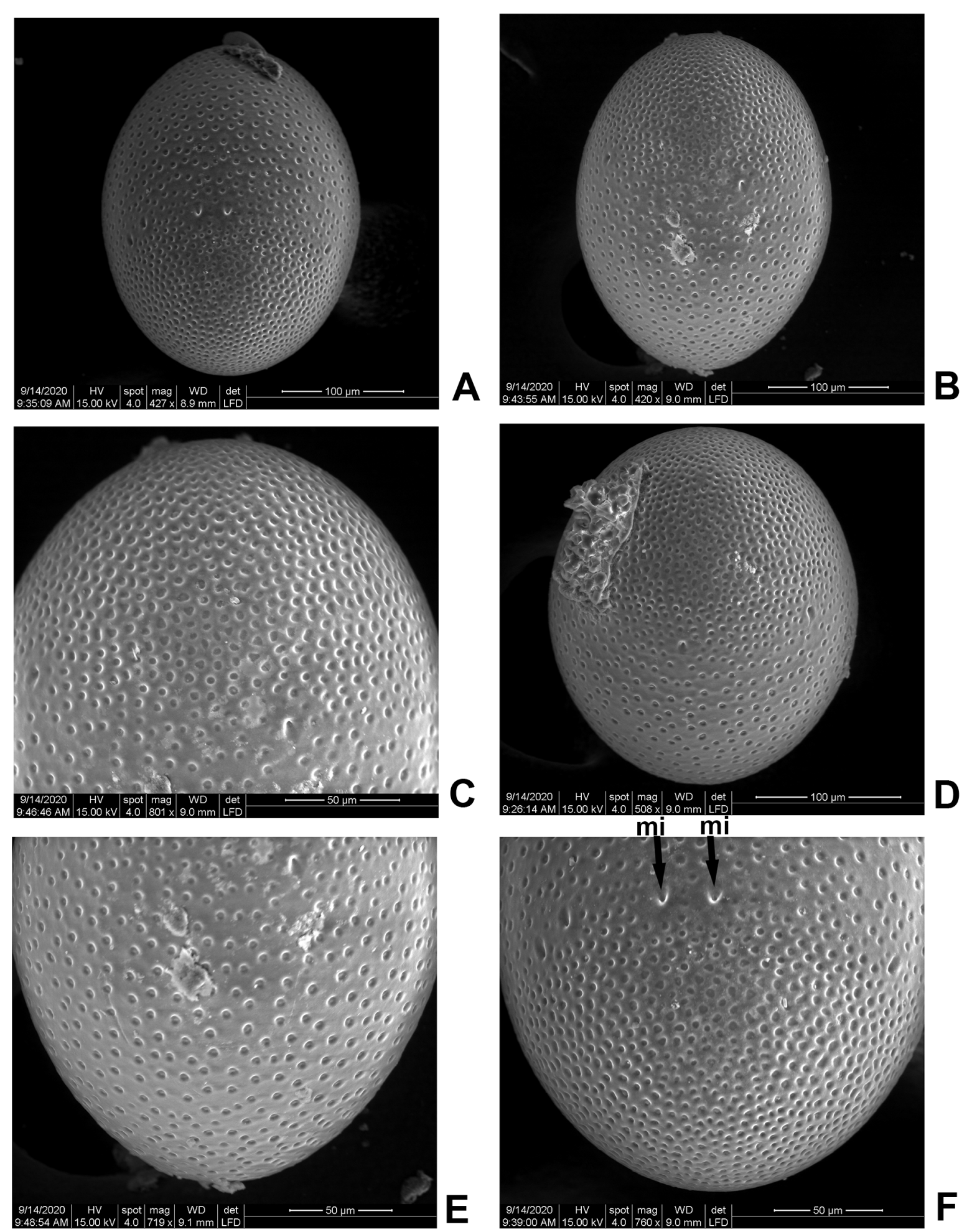

Fig. 5. Chinoperla changjiangensis sp. nov., eggs. A. Entire egg, lateral view. B. Entire egg, lateral view. C. Lid end, lateral view. D. Lid end, apical view. E. Collar end, lateral view. F. Micropyles (indicated by arrows). Abbreviations: see Material and methods. 
spine groupings. In addition, the apical lobe of the aedeagus of $C$. changjiangensis sp. nov. is covered with distinct small spines, whereas in C. biprojecta it is bare.

Besides the distinctly different armatures of the aedeagal sac, $C$. changjiangensis sp. nov. can easily be distinguished from the sympatric $C$. nigrifrons by external morphology: the anterolateral extension of the interocellar marking is moderately angled, not so rounded or heart-shaped as in C. nigrifrons; the hemitergal lobe is evenly tapering in lateral view, not like the medially abruptly tapering lobe in C. nigrifrons that could be observed both in dorsal and lateral aspects. Both of these characters were overlooked in previous studies (compare Sivec \& Zwick 1989: fig. 3b and Figs 1, 3B, D-E vs Figs 6B-E, $8 \mathrm{~A}-\mathrm{B})$.

Chinoperla mengmanensis Qian \& Du, 2012

Chinoperla mengmanensis Qian \& Du, 2012: 117, figs 1-5 (original description of the male).

Chinoperla mengmanensis - Yang \& Li 2018: 36 (catalog). - Chen \& Hou 2020: 167, figs 10-14 (supplementary descriptions of male and female).

\section{Distribution}

China: Yunnan Province, two localities in Mengla County.

\section{Remarks}

This species is characterized by the male aedeagus having a pair of spiny lateroapical lobes and a membranous apical lobe (Qian \& Du 2012; Chen \& Hou 2020). The female subgenital plate is unproduced but with a pale semicircular posteromedial area, which was recently described by Chen \& Hou (2020) from Mengla County of Yunnan.

Chinoperla nigrifrons (Banks, 1939)

Figs 6-10

Ochthopetina nigrifrons Banks, 1939: 449, fig. 73 (original description).

Sinoperla furcomacula Wu, 1973: 110, figs 91-93 (original description).

Ochthopetina nigrifrons - Illies 1966: 274 (catalog).

Chinoperla furcomacula - Zwick \& Sivec 1980: 130 (transferred from Sinoperla). — Zwick 1982: 168 (synopsis). - Sivec et al. 1988: 54 (provisionally possible conspecifity with C. nigrifrons). — Sivec \& Zwick 1989: 14 (three theories about possible synonymy or distinctiveness with C. nigrifrons).

Chinoperla nigrifrons - Sivec et al. 1988: 54 (transferred from Ochthopetina, provisionally possible conspecifity with C. furcomacula). — Sivec \& Zwick 1989: 14, fig. 3a, c-e (redescription of male with uneverted aedeagus and female based on types). — Du et al. 1999: 62 (catalog). — Yang \& Li 2018: 36 (catalog).

\section{Diagnosis}

Head with a heart-shaped dark brown patch and a subtriangular dark brown spot. Male tergum 9 with a trumpet-shaped median sclerite. Hemitergal processes medially indented in lateral view. Aedeagal tube with a T-shaped sclerotized dorsal marking. Aedeagal sac dorsoapically with a low membranous median lobe; ventrobasally with a large patch of spinules; ventroapically with one long and one shorter spine, or the two of equal length; apically with a long straight spine and a large membranous lobe; laterally with dense large, curved spines arranged on each side. Posterior margin of female sternum 8 slightly produced, forming a small subtriangular subgenital plate with an apical notch. 


\section{Material examined}

\section{Holotype}

CHINA • đ̃; "Hainan, Ta Han" [Hainan Province, Qiongzhong Li and Miao Autonomous County, located in Limushan Town]; 23 Jun. 1935; L. Gressitt leg.; MCZ Type 22693.

\section{Paratypes}

CHINA • 1 क ; same locality data as for holotype; 2 Aug. 1935; L. Gressitt leg.; MCZ・ 1 क; same locality data as for holotype; 13 Jul. 1935; L. Gressitt leg.; MCZ.

\section{Other material}

CHINA 1 ภ, 1 (holotype and paratype of S. furcomacula); "Kwangtung, Hainan, Tung-shih" [Hainan Province belonging to Guangdong at that time, Wuzhishan City, Tongshen Town]; alt. $350 \mathrm{~m} ; 27$ May

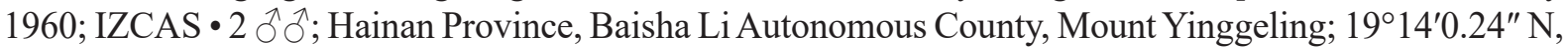
109²6'27.96" E; alt. 430 m; 1 Apr. 2013; Yu-Yu Wang and Yun-Lan Jiang leg.; HIST.
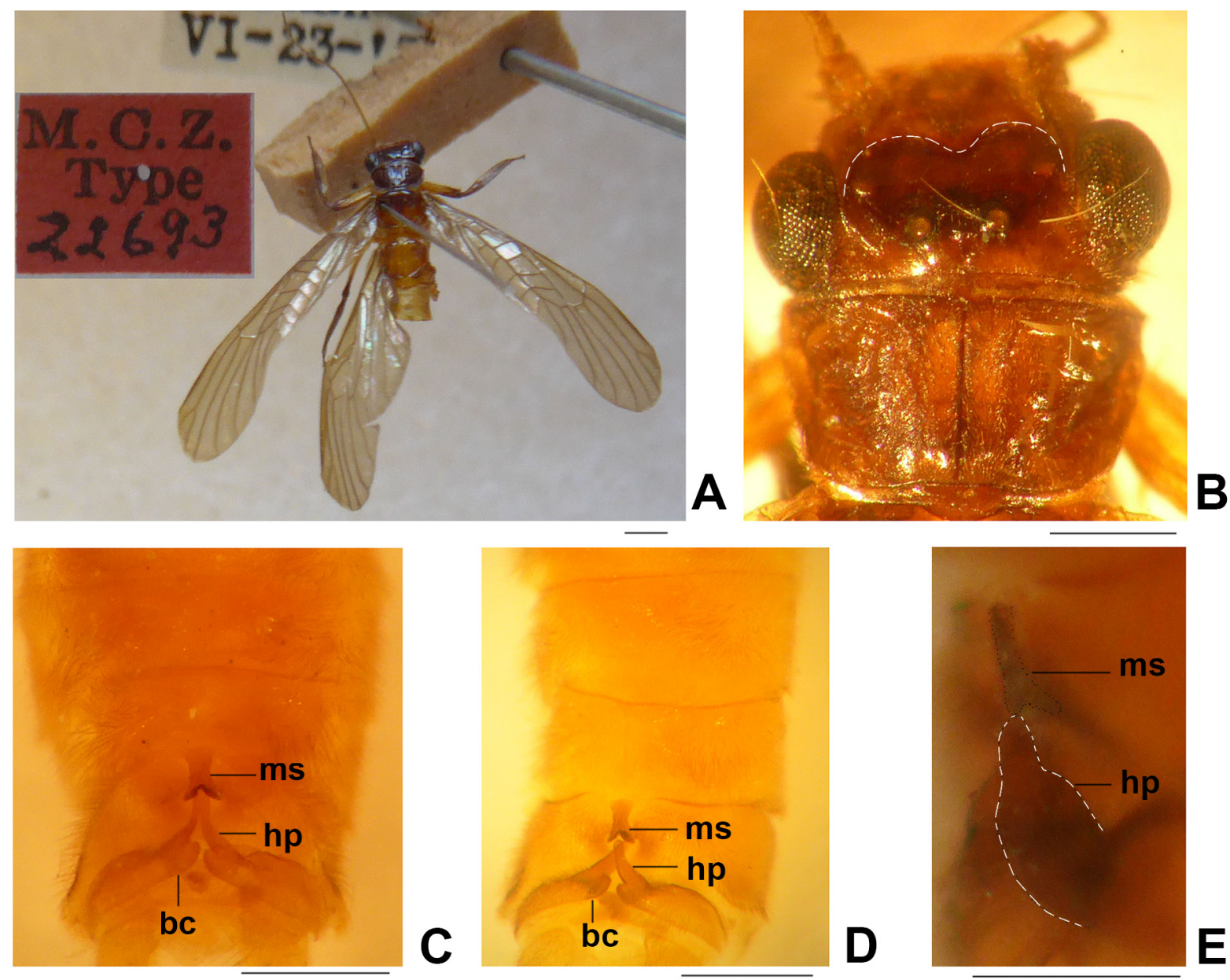

Fig. 6. Chinoperla nigrifrons (Banks, 1939), ô, holotype (MCZ Type 22693). A. Adult habitus, dorsal view. B. Head and pronotum, dorsal view. C. Terminalia, dorsal view. D. Cleared terminalia, dorsal view. E. Cleared terminalia, lateral view. Abbreviations: see Material and methods. Scale bars: $A=1.0 \mathrm{~mm}$; $\mathrm{B}-\mathrm{E}=0.5 \mathrm{~mm}$. 


\section{Redescription}

\section{Male}

Adult habitus (Figs 6A-B, 8C, 9A). General color brown. Forewing length 7.7-8.0 mm, hindwing length 6.7-7.1 mm. Head brownish, with a dark brown heart-shaped spot, but specimens from Mount Yinggeling with a long brown band located on the occiput, and with a subtriangular dark brown spot in front of M-line; biocellate, ocelli about 3 diameters apart of each other, slightly closer to each other than

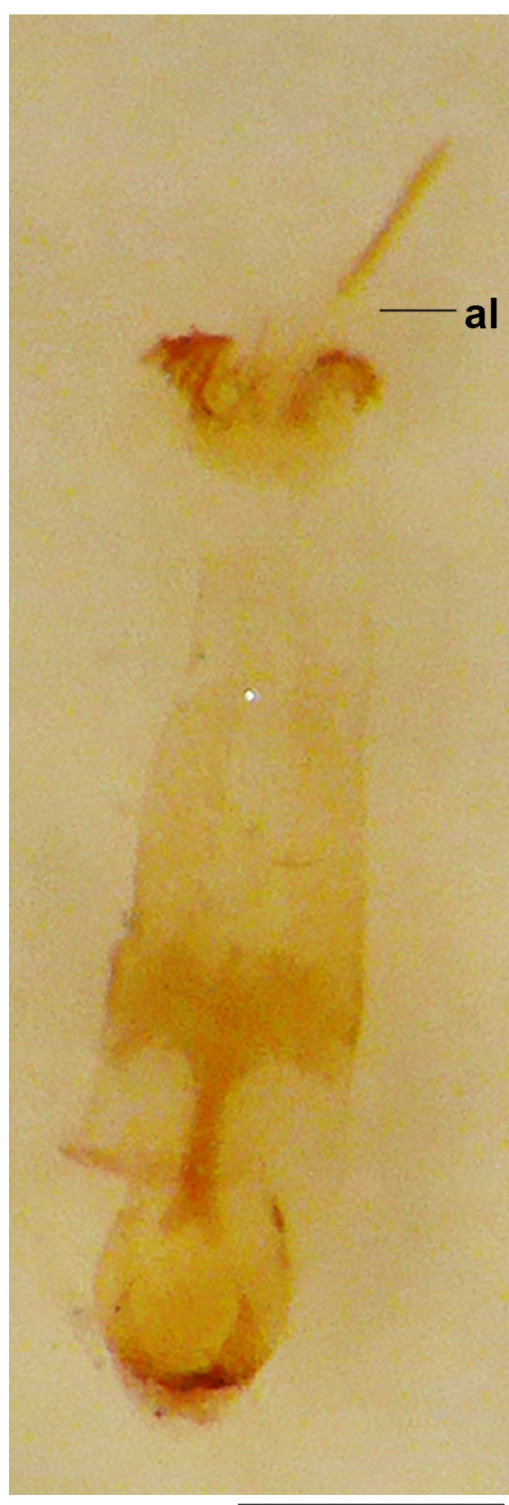

A

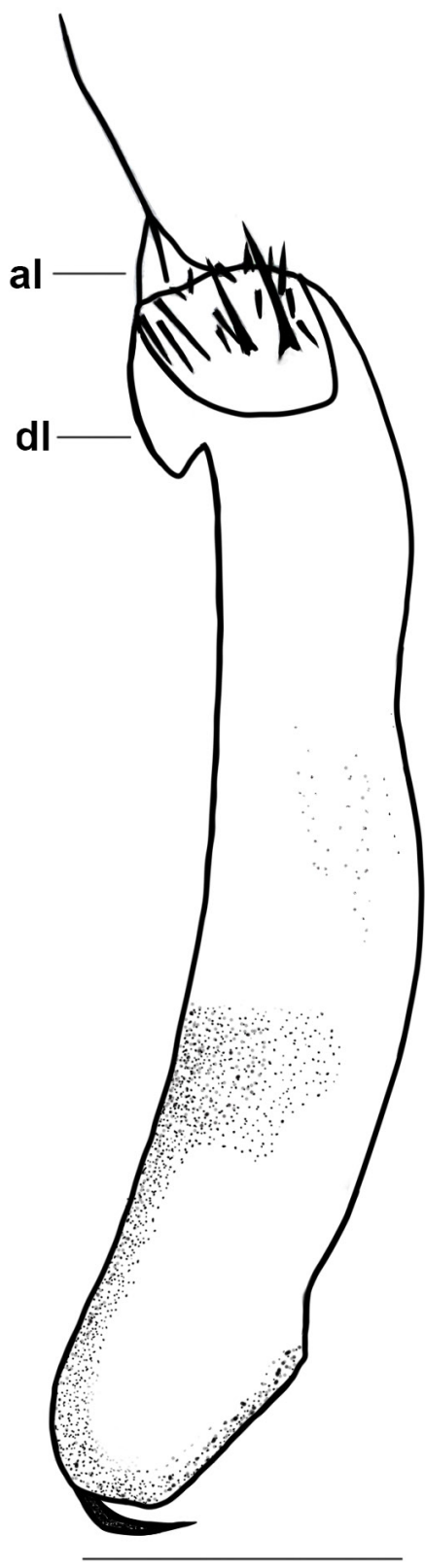

B

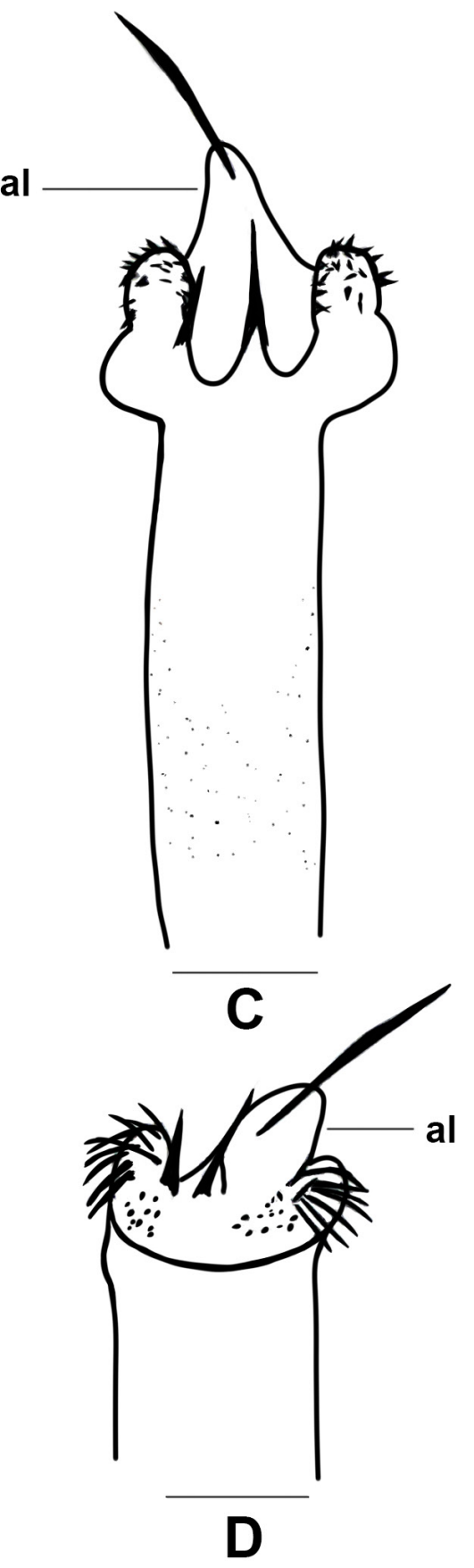

Fig. 7. Chinoperla nigrifrons (Banks, 1939), $\widehat{\jmath}$, holotype (MCZ Type 22693). A. Aedeagus, dorsal view. B. Aedeagus, lateral view. C. Aedeagal sac, ventral view. D. Apex of aedeagal sac, oblique ventral view. Abbreviations: see Material and methods. Scale bars $=0.25 \mathrm{~mm}$. 
to the compound eye; antennae brown. Pronotum trapezoidal, brown with paler lateral margin and with darker, distinct rugosities; anterior corners pointed but posterior corners obtuse. Legs generally brown, proximal part of femora mostly lighter; wings subhyaline and brownish, veins brown, Sc of forewing short, typical of the genus (Fig. 8C); cerci brownish.

Aвdomen (Figs 6C-E, 8A-B, 9B-E). Sterna 3-5 with hair brushes. Dark median sclerite of tergum 9 trumpet-shaped, about half as long as the segment, heavily sclerotized, distinctly forked distally with two sharp points. Hemitergal processes slender, about $2.5 \times$ as long as basal width, distinctly narrowing subapically; medially indented in lateral view; basal callus fully covered by sensilla basiconica.

AedEAGus (Figs 7, 10). Aedeagal tube partially sclerotized dorsally, forming a distinctly T-shaped marking on the holotype (Fig. 7A-B), but marking in specimens from Mount Yinggeling indistinct, well seen only in lateral view (Fig.10A-B). Fully everted sac as long as the tube, curved dorsad; ventroapical and

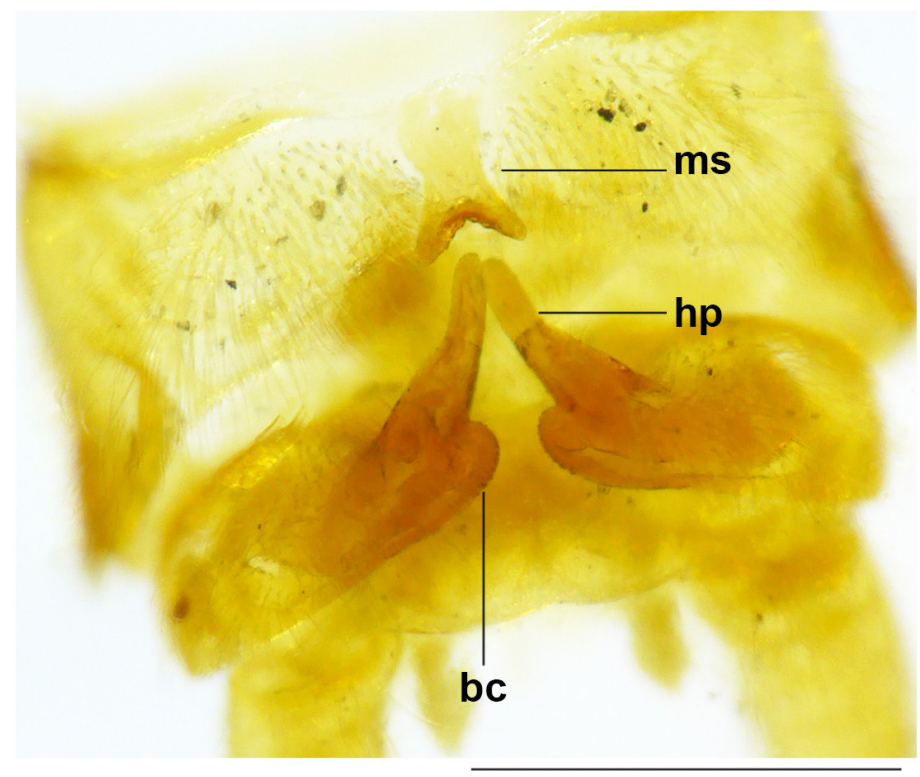

A

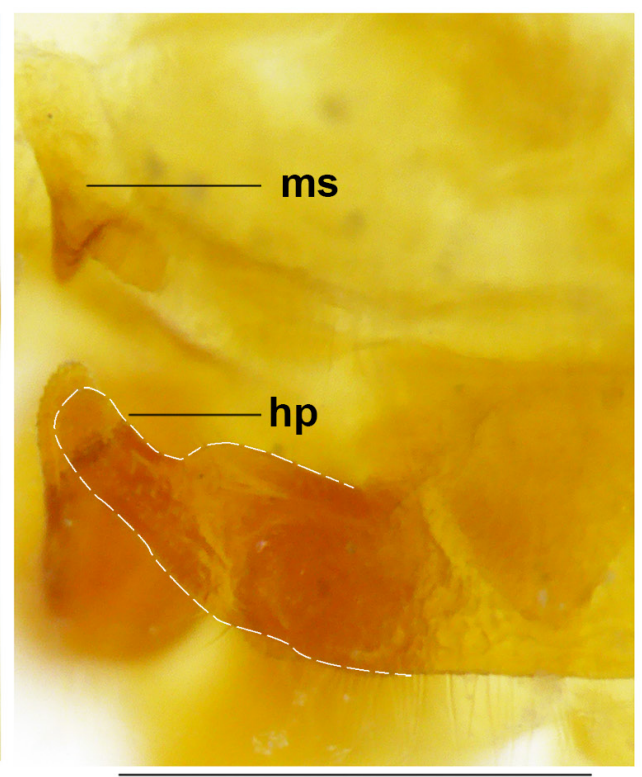

B

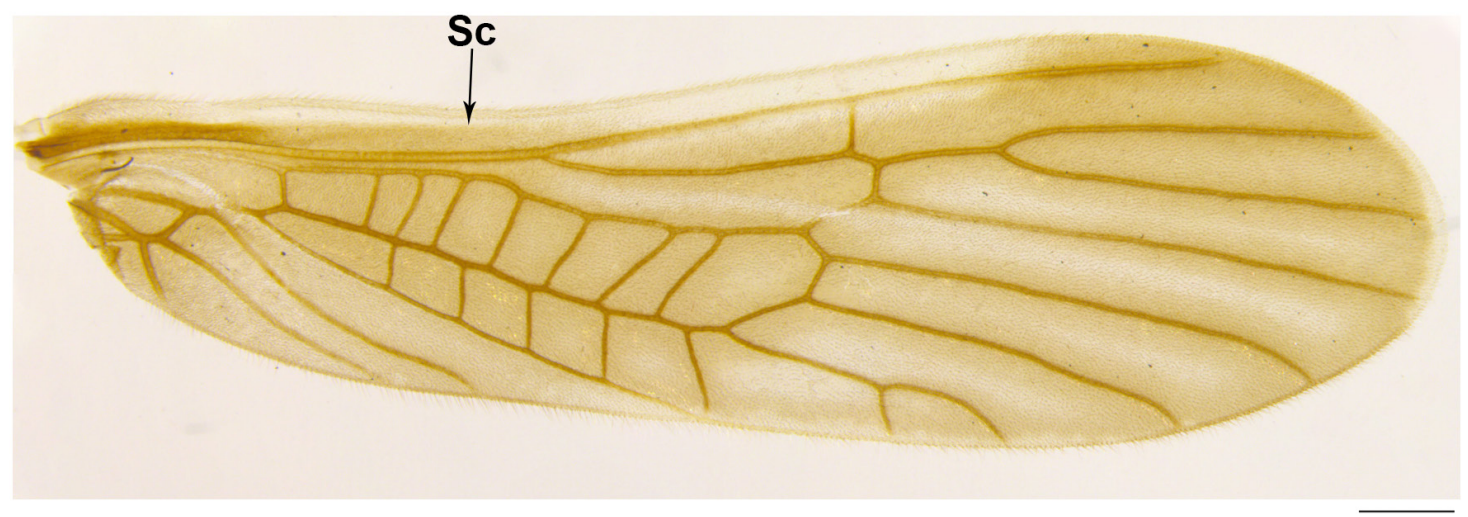

C

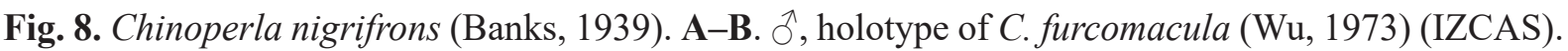
A. Cleared terminalia, dorsal view. B. Cleared terminalia, lateral view. - C. $\widehat{\jmath}$ from Mount Yinggeling (HIST), forewing. Abbreviations: see Material and methods. Scale bars $=0.5 \mathrm{~mm}$. 
dorsoapical surface heart-shaped in specimens from Mount Yinggeling (Fig. 10), less definite in the holotype (Fig. 7); dorsoapical surface with a small bulgy membranous median lobe; a single large spine about as long as $1 / 4$ aedeagus length, and a large membranous lobe medially at apex, slightly directed dorsally; ventral surface with a large basal patch of spinule, and one long and one shorter subapical spines (Fig. 7) but in fresh specimens from Mount Yinggeling the two of approximately equal length (Fig. 10); lateroapical part with dense, large and curved spines arranged on each side.

\section{Distribution}

China: Hainan Province, found in three counties.

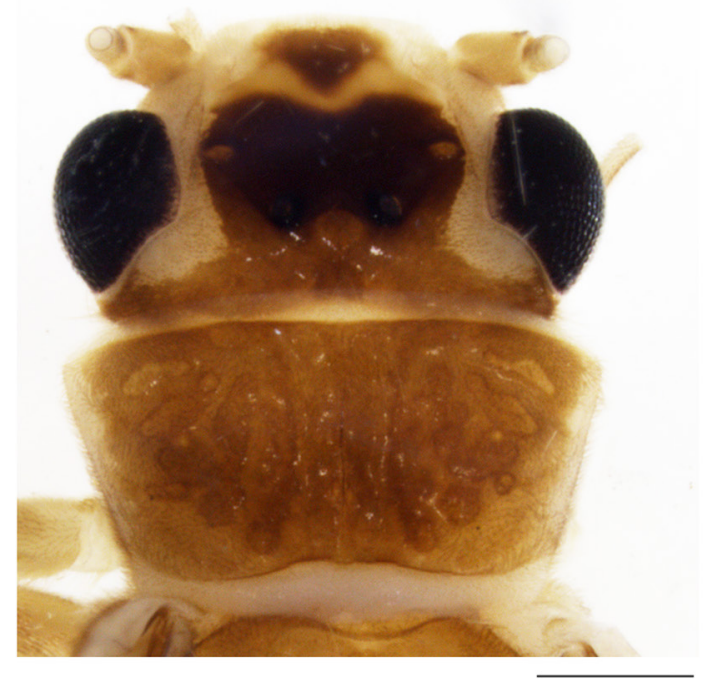

A

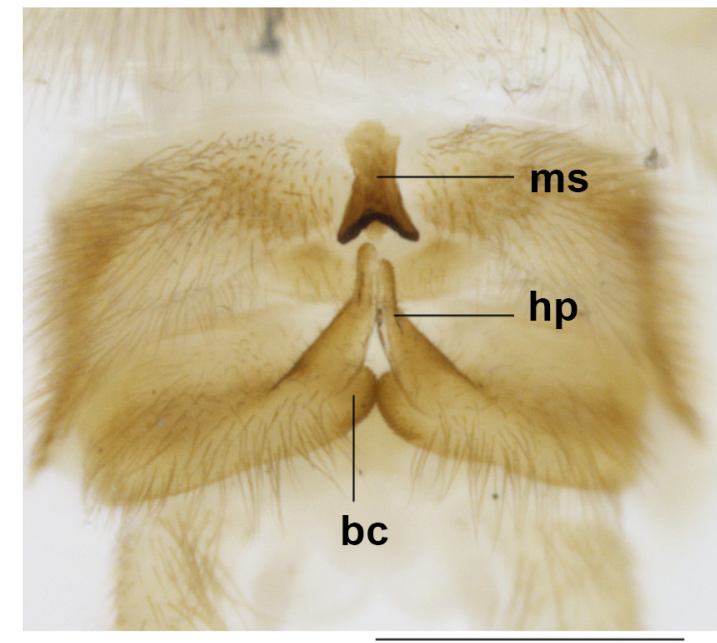

C

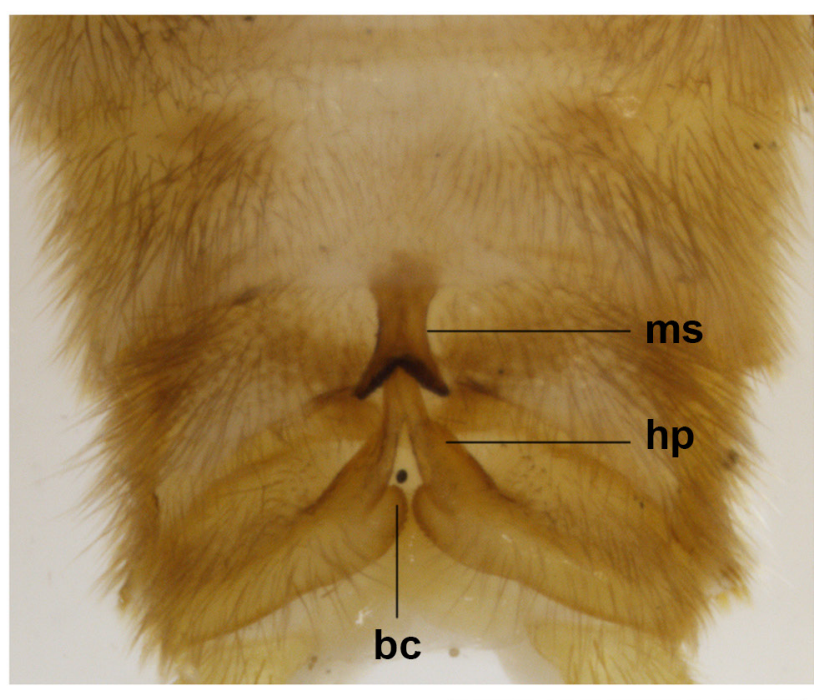

B

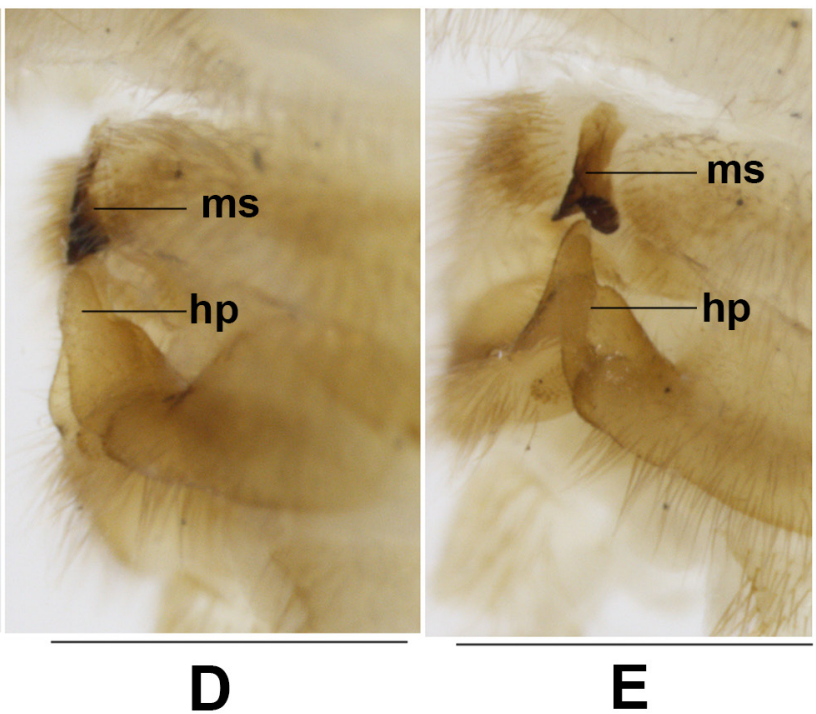

Fig. 9. Chinoperla nigrifrons (Banks, 1939), $\widehat{\partial}$ from Mount Yinggeling (HIST). A. Head and pronotum, dorsal view. B. Terminalia, dorsal view. C. Cleared terminalia, dorsal view. D. Cleared terminalia, lateral view. E. Cleared terminalia, oblique lateral view. Abbreviations: see Material and methods. Scale bars = $0.5 \mathrm{~mm}$. 


\section{Remarks}

We carefully compared the type specimens of $O$. nigrifrons deposited in MCZ with the illustrations in Sivec \& Zwick (1989). The head pattern, direction of antennae and shape of the pronotum of the female paratype collected on 13 July 1935 are consistent with those illustrated in Sivec \& Zwick (1989: fig. 3a, $\mathrm{d}-\mathrm{e}$ ). The figures of the terminalia and vagina also refer to the same female paratype, because the second female paratype collected on 2 August 1935 had not been dissected, and its sternum 9 is more narrow. The figure of the male terminalia in Sivec \& Zwick (1989: fig. 3b) shows a shallow apical notch of the median sclerite of tergum 9 , and tapering and curving hemitergal processes without a straight apical half. These characters are consistent with those in the male paratype, that is not conspecific with the holotype and has been reassigned to C. changjiangensis sp. nov. above (Fig. 3B-E). However, the small basal sclerite in the aedeagus of the holotype (Fig. 7B) corresponds to that illustrated in Sivec \& Zwick (1989: fig. 3c). Therefore, we believe that the half-everted aedeagus of the holotype, the terminalia of the male paratype (C. changjiangensis sp. nov.), and the head, pronotum, sterna 7-9 and vagina of the female paratype of Chinoperla nigrifrons were redescribed by Sivec \& Zwick (1989). Color photographs and
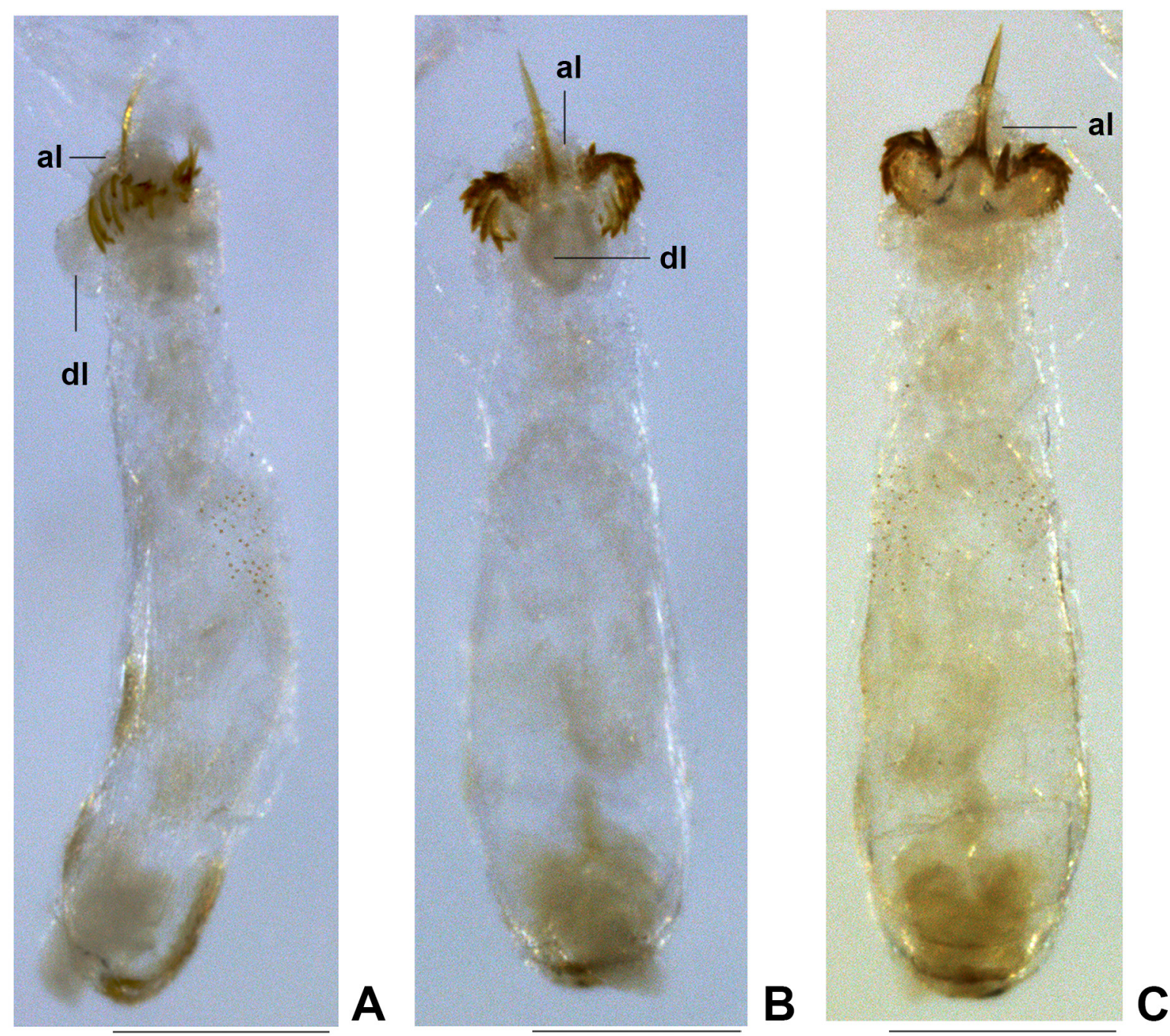

Fig. 10. Chinoperla nigrifrons (Banks, 1939), đ̂ from Mount Yinggeling (HIST). A. Aedeagus, lateral view. B. Aedeagus, dorsal view. C. Aedeagus, ventral view. Abbreviations: see Material and methods. Scale bars $=0.25 \mathrm{~mm}$. 
MO R.R. et al., Review of Chinoperla (Plecoptera: Perlidae: Perlinae) from China

illustrations of the male holotype are provided in the present study (Figs 6-7). The characteristics of both female paratypes agree well with the description and illustrations provided by Sivec \& Zwick (1989).

We checked the types of S. furcomacula in IZCAS, but the aedeagus of S. furcomacula with the holotype label was difficult to fully evert due to the poor condition of the specimen. Based on the original description and redescription of $C$. nigrifrons in the present study, we believe that the holotype of $S$. furcomacula is conspecific with the holotype of $O$. nigrifrons, and is therefore a junior synonym of $C$. nigrifrons (Banks 1939; Wu 1973; Sivec et al. 1988; Sivec \& Zwick 1989). The two recently collected males from Hainan Province examined in this study agree well with the type specimens in general characteristics such as head pattern, lateral aspect of the hemitergal lobes, and armatures of the aedeagus. However, these fresh specimens from Mount Yinggeling show slight differences in the head pattern and aedeagus, as they have a long brown posterior band on the head, and the two ventroapical spines of the aedeagal sac are straight and nearly equal in length. We believe this brown occipital band disappears in fully aged adults, such as the holotype. Similar differences were documented in the case of Kamimuria guangxia Li \& Wang, 2013 and Neoperla lihuae Li \& Murányi, 2014 (Wang et al. 2013; Li et al. 2014). The differences in the aedeagal armatures can be regarded as intraspecific differences. We provide illustrations of the fully everted sac of the $C$. nigrifrons holotype and the fresh adults to allow a reliable identification for future studies (Figs 7, 10).

Unfortunately, the paratype female of S. furcomacula in IZCAS is badly damaged and difficult to study. According to the original description and figures of S. furcomacula (Wu 1973: fig. 93), the terminalia of the paratype female distinctly differ from those of $C$. nigrifrons by the unmodified subgenital plate. Sivec \& Zwick (1989) drew up three possibilities for the specific identity of this female; we support the third, which suggests that the paratype female may not be conspecific with the holotype of $S$. furcomacula. Further specimens from Hainan are needed to confirm the identity of the female.

Chinoperla nigroflavata (Wu, 1948)

Sinoperla nigroflavata Wu, 1948: 78, figs 8-9 (original description of the male).

Sinoperla nigroflavata - Illies 1966: 274 (catalog).

Chinoperla nigroflavata - Zwick 1980: 130 (transferred from Sinoperla). —Zwick 1982: 167 (synopsis). — Sivec et al. 1988: 54 (synopsis). — Du et al. 1999: 62 (catalog). — Yang \& Li 2018: 36 (catalog).

\section{Distribution}

China: Fujian Province, known only from the (now lost) holotype.

\section{Remarks}

The details of the aedeagal structures of this species are still unknown and the type material is lost (Wu 1948; Du et al. 1999; Yang \& Li 2018). No new material was available for the present study, but it seems to differ from the remaining Chinese species of Chinoperla based on the absence of the short Sc of the forewing and the shape of the dark median sclerite of tergum 9 (Wu 1948: figs 8-9). Chinoperla gorohovi Sivec \& Stark, 2010 from Guangdong and Vietnam is easily distinguishable from C. nigroflavata by the slender nail-shaped median sclerite with a slightly enlarged apex (Fig. 11B-D).

Chinoperla gorohovi Sivec \& Stark, 2010

Figs 11-14

Chinoperla gorohovi Sivec \& Stark, 2010: 63, figs 1-4 (original description of the male). 


\section{Diagnosis}

Head with a dark brown central spot subdivided by the lighter M-line. Male tergum 9 with a slender nailshaped median sclerite, having a slightly enlarged tip. Aedeagal tube with a fishtail-shaped sclerotized dorsobasal marking. Aedeagal sac straight, dorsomedially with two differently sized membranous lobes, and apically with a membranous lobe bearing a long median spine and two shorter lateral spines. Posterior margin of female sternum 8 barely produced, forming a small triangular subgenital plate. Eggs dark brown, teardrop-shaped with long and slender collar, and petiolate anchor.

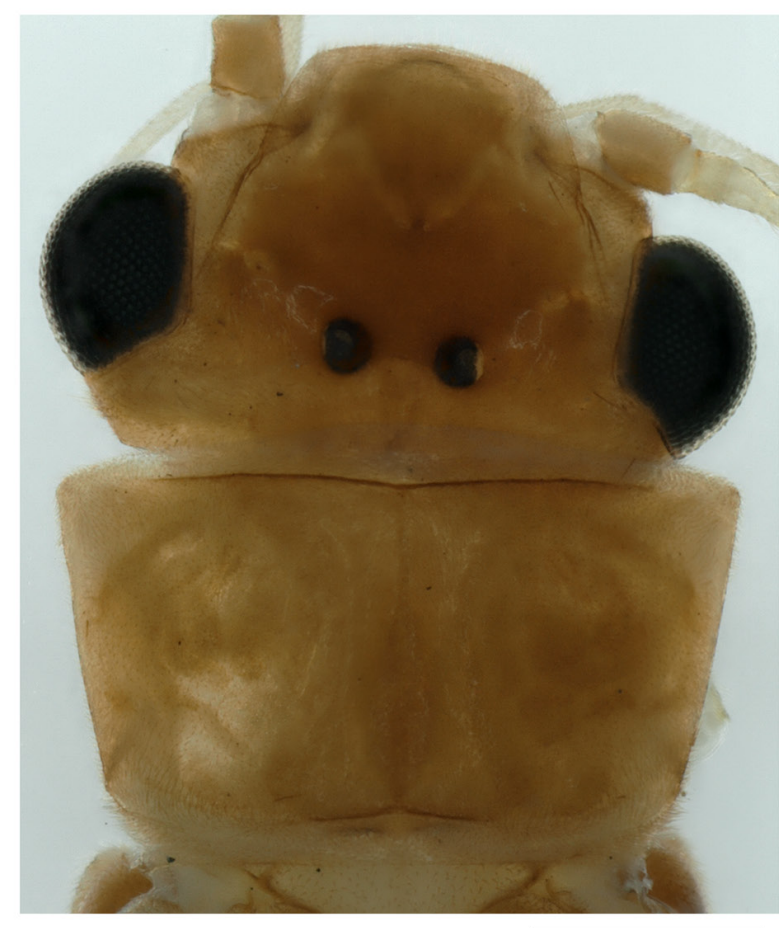

A

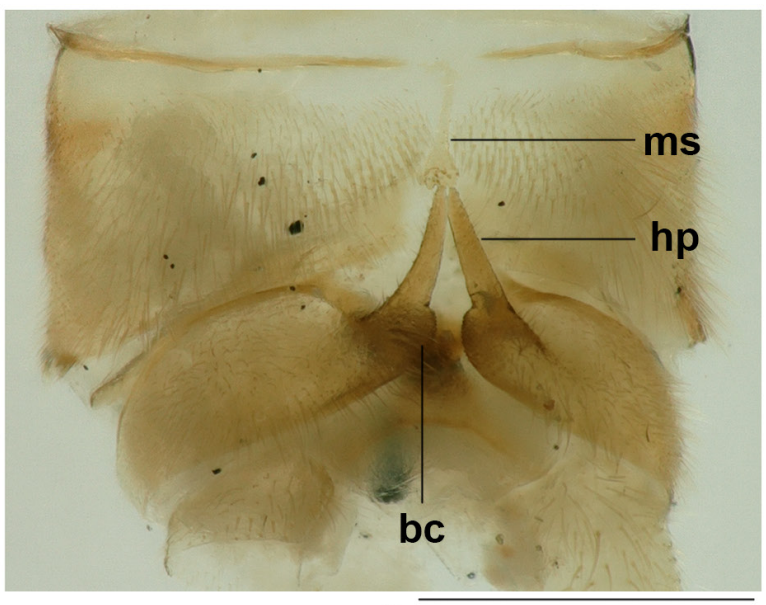

C

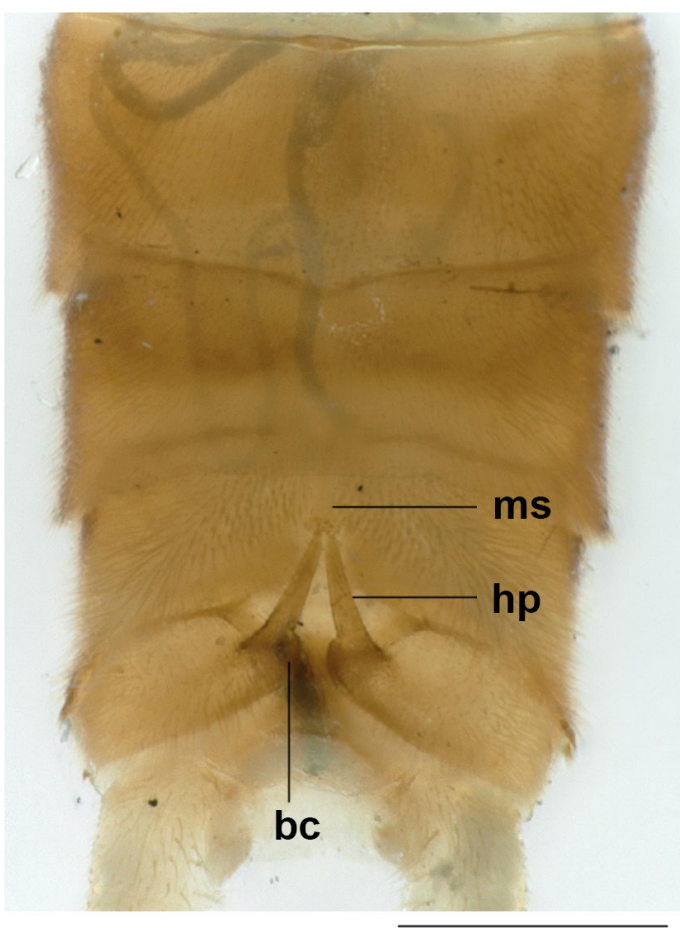

B

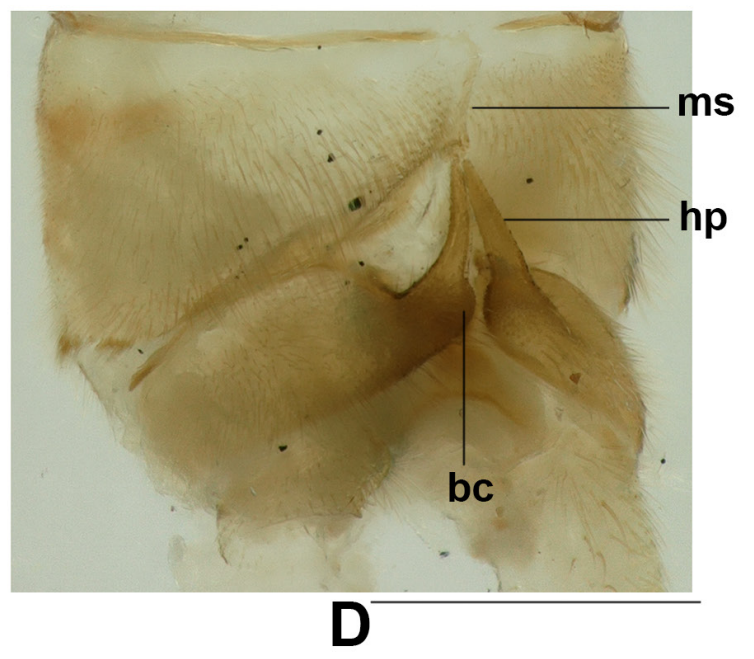

Fig. 11. Chinoperla gorohovi Sivec \& Stark, 2010, $\widehat{\jmath}$ (CAU). A. Head and pronotum, dorsal view. B. Terminalia, dorsal view. C. Cleared terminalia, dorsal view. D. Cleared terminalia, oblique lateral view. Abbreviations: see Material and methods. Scale bars $=0.5 \mathrm{~mm}$. 


\section{Material examined}

CHINA • 1 ô, 1 क; Guangdong Province, Guangzhou City, Zengcheng District, Mt. Nankunshan;

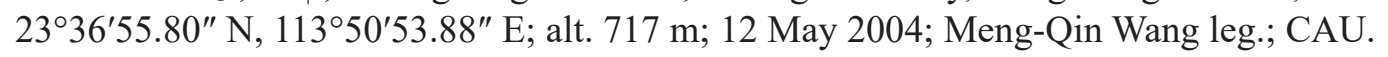

\section{Description}

Male (complementary description)

Adult Habitus (Fig. 11A). General color pale brown. Forewing length ca $9.5 \mathrm{~mm}$, hindwing length ca $8.3 \mathrm{~mm}$. Head pale brown, with a dark brown central spot subdivided by the lighter M-line; biocellate, ocelli about twice the diameter apart of each other, but still closer to each other than to the compound eye; antennal scape brown, flagellum brownish. Pronotum pale brown, trapezoidal, with obscure darker rugosities and midline; anterior corners pointed but posterior corners obtuse. Legs brown but basal half of femora pale brown; wings subhyaline and yellowish brown, veins brown, Sc of forewing short, typical of the genus; cerci pale.

AвDomen (Fig. 11B-D). Sterna 3-5 with hair brushes. Dark median process of tergum 9 sclerotized, slender nail-shaped, about 3 times as long as wide, and slightly enlarged on posterior margin; posterior portion covered by several tiny, brown warts. Hemitergal processes slender, about $2.5 \times$ as long as basal width, with a pointed tip; triangular in lateral view; basal callus with patch of sensilla basiconica.
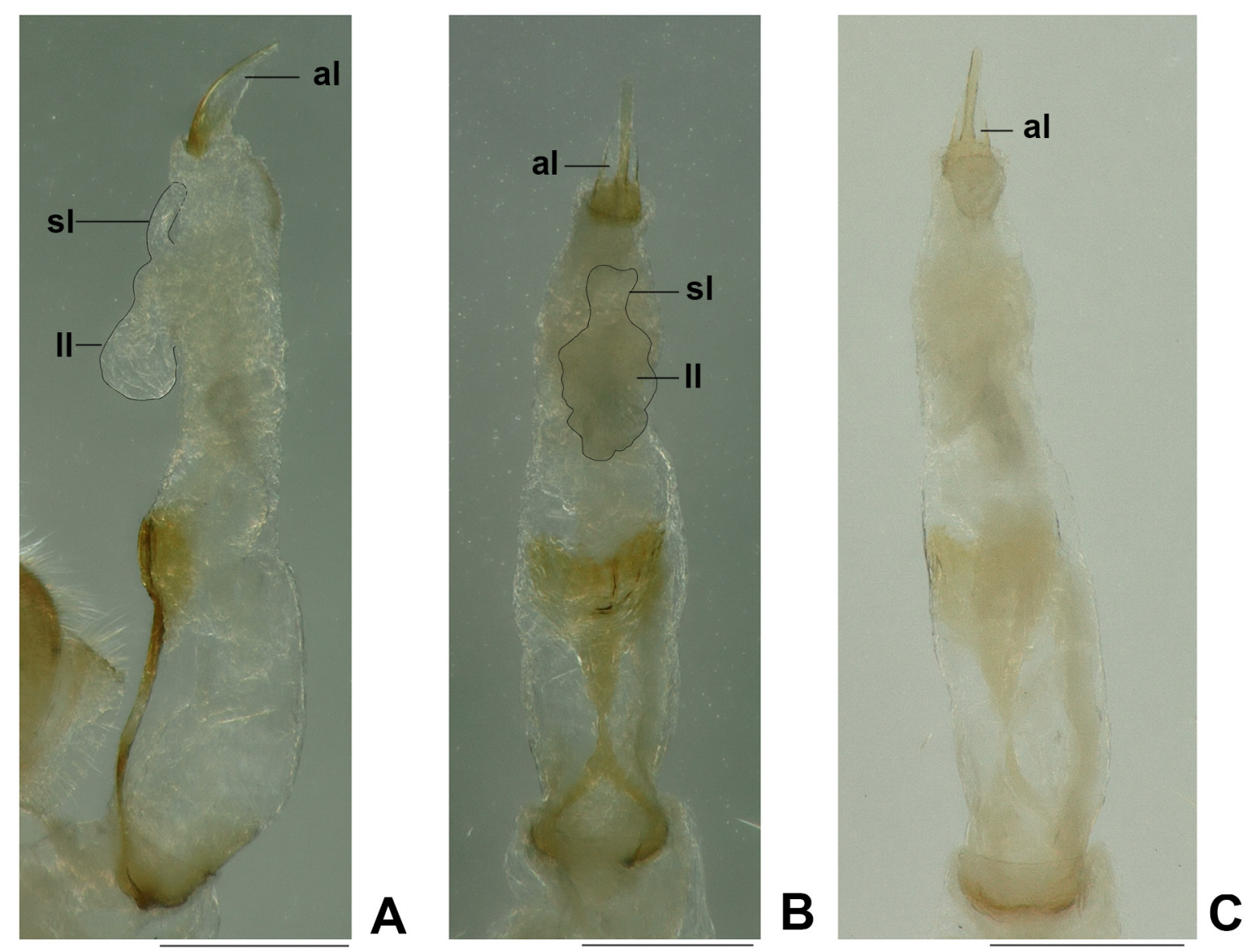

Fig. 12. Chinoperla gorohovi Sivec \& Stark, 2010, § (CAU). A. Aedeagus, lateral view. B. Aedeagus, dorsal view. C. Aedeagus, ventral view. Abbreviations: see Material and methods. Scale bars $=0.25 \mathrm{~mm}$. 
AEDEAGus (Fig. 12). Aedeagal tube partially sclerotized dorsobasally, forming a fishtail-shaped marking. Fully everted sac as long as the tube, straight; a large and a small membranous lobe located in dorsomedial portion, their apex points to the base and tip of the aedeagus, respectively; ventroapical surface with a slightly swollen and sclerotized area, distinct in lateral view; a basally sclerotized but mostly membranous apical lobe bears a long spine about as long as $1 / 4$ aedeagus length.
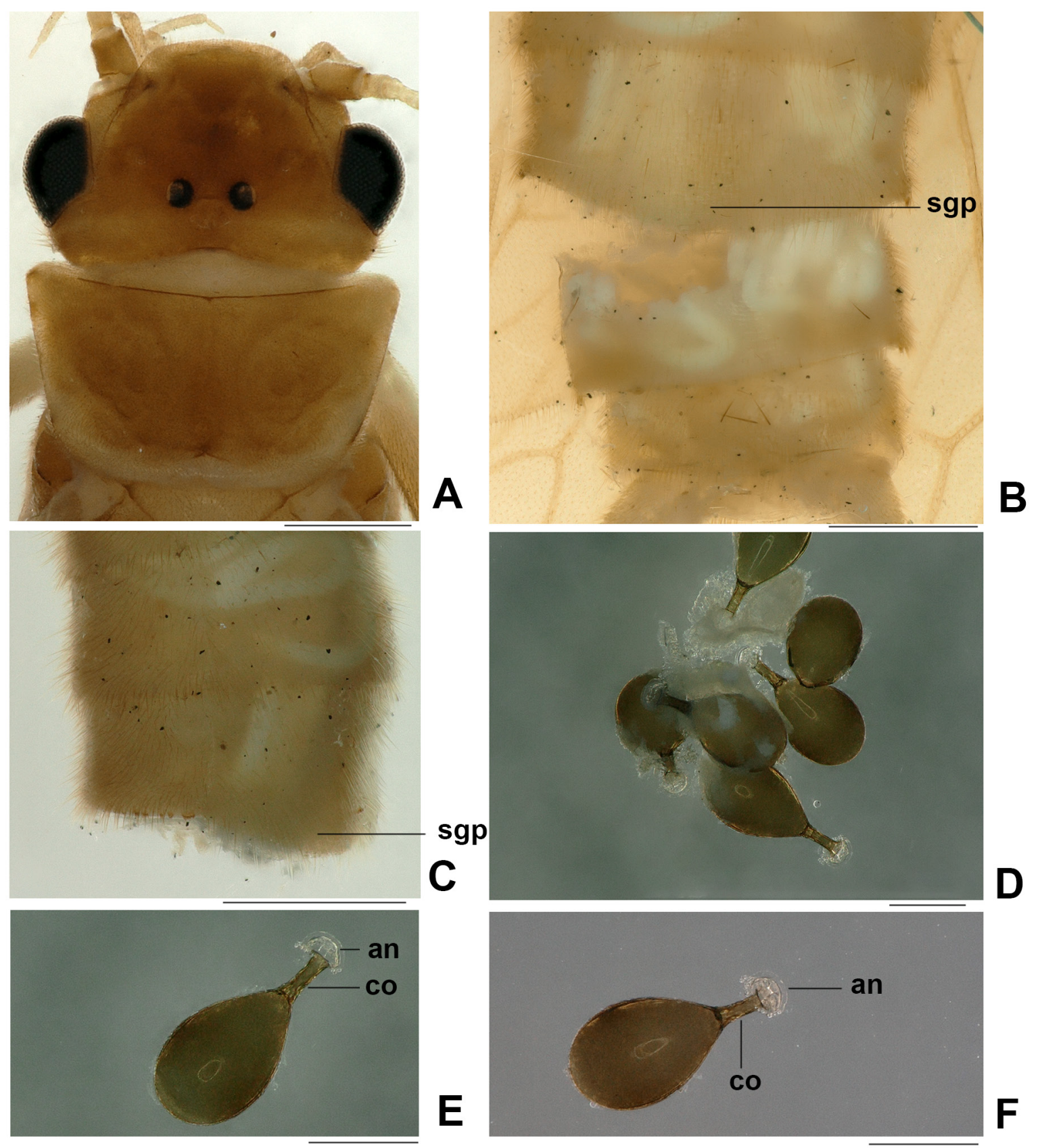

Fig. 13. Chinoperla gorohovi Sivec \& Stark, 2010, $q$ (CAU). A. Head and pronotum, dorsal view. B. Terminalia, ventral view. C. Terminalia, lateral view. D. Eggs. E. Entire egg, lateral view. F. Entire egg, oblique lateral view. Abbreviations: see Material and methods. Scale bars: A-C $=0.5 \mathrm{~mm}$; D-F $=$ $0.25 \mathrm{~mm}$. 


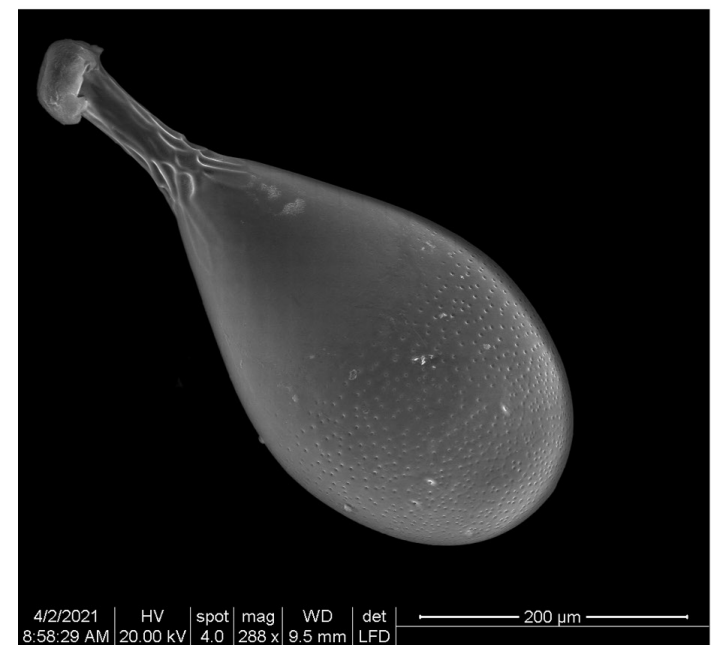

A

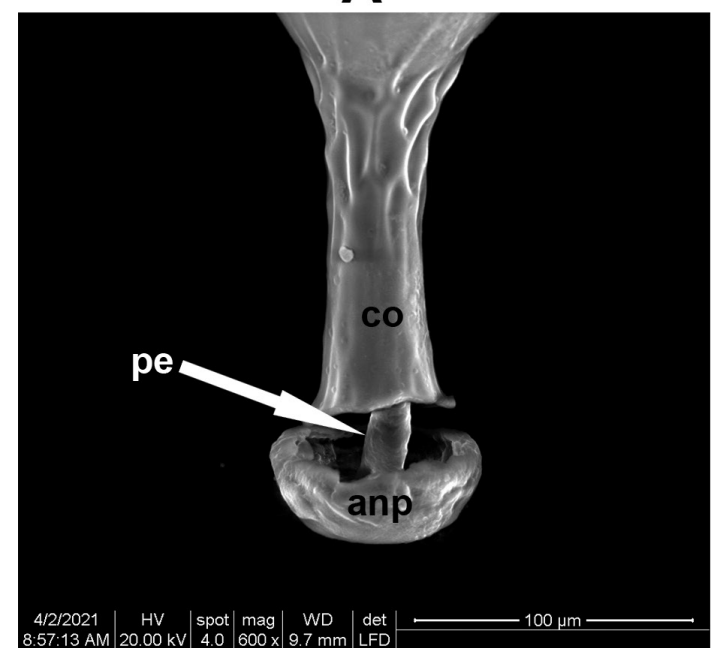

C

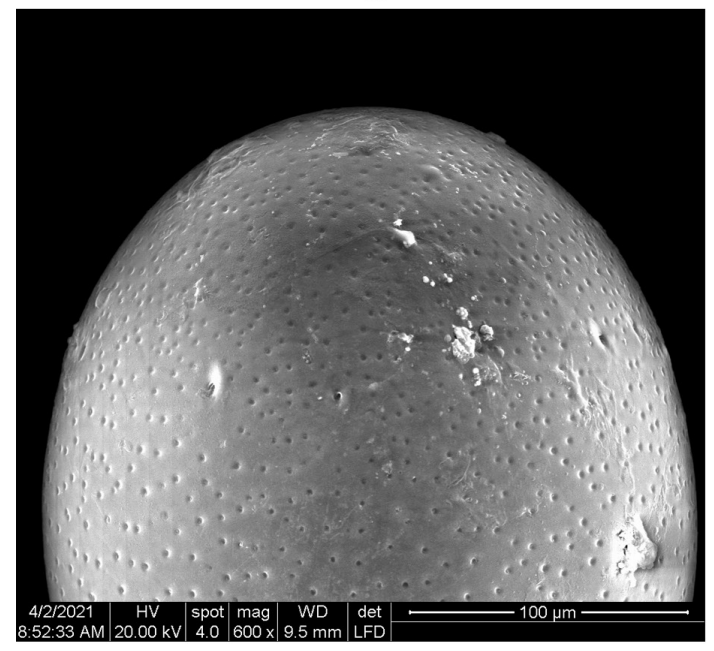

E

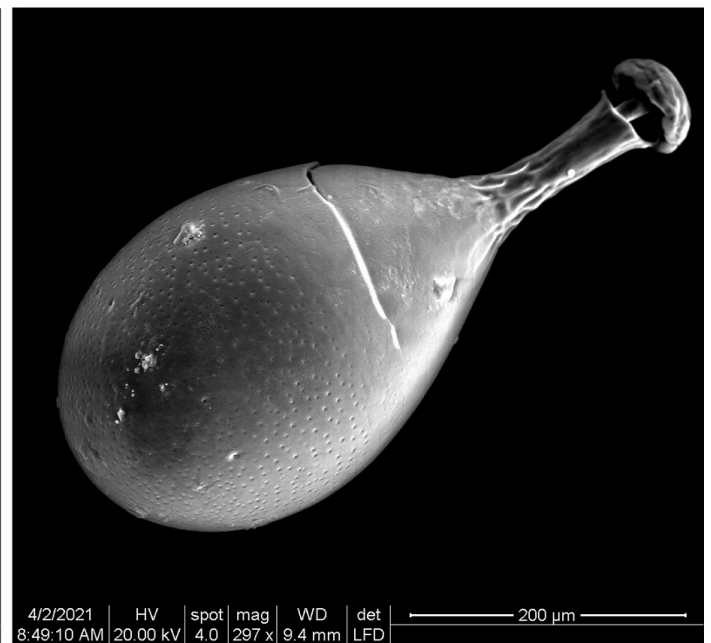

B

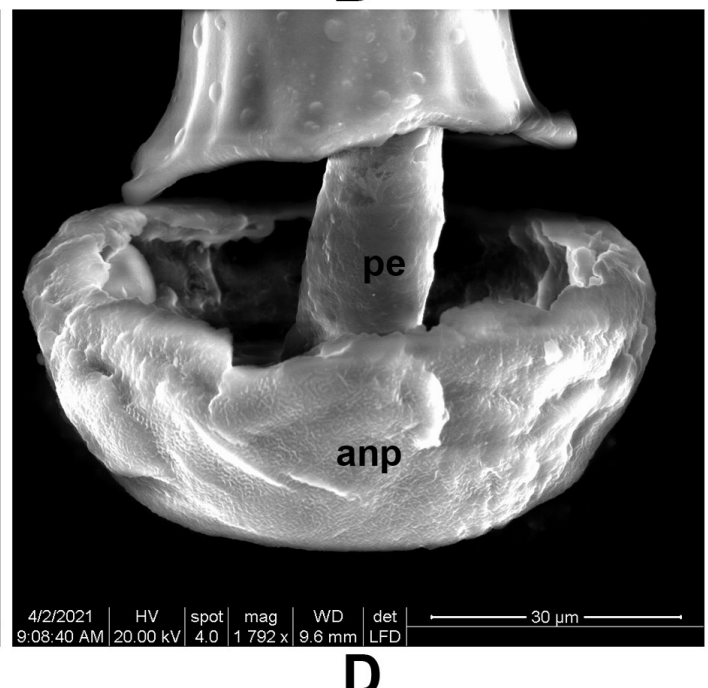

D

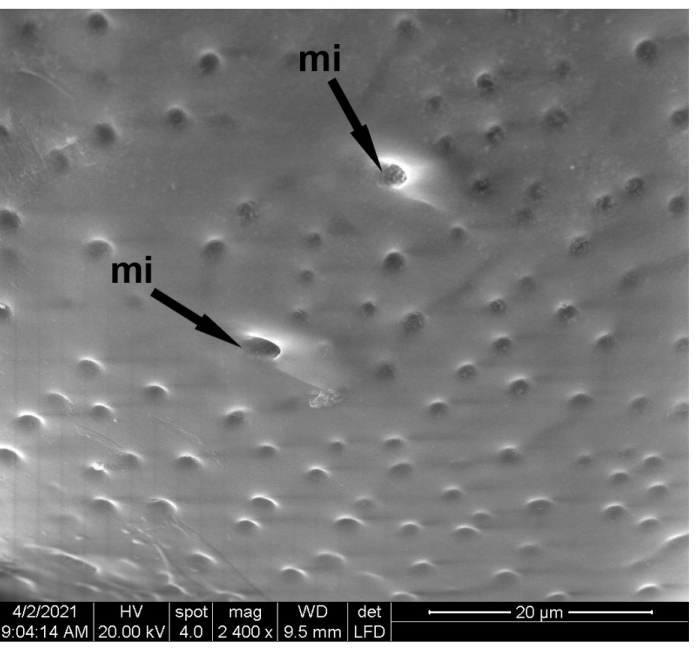

$\mathbf{F}$

Fig. 14. Chinoperla gorohovi Sivec \& Stark, 2010, eggs. A. Entire egg, lateral view. B. Entire egg, lateral view. C. Collar and anchor, lateral view. D. Anchor, lateral view. E. Lid end, lateral view. F. Micropyles (indicated by arrows). Abbreviations: see Material and methods. 
Female

Adult Habitus(Fig. 13A). Forewing length ca $10.5 \mathrm{~mm}$, hindwing length ca $9.5 \mathrm{~mm}$. Habitus generally similar to the male.

AвDOMEN (Fig. 13B-C). Subgenital plate of sternum 8 slightly produced, short but wide triangular, without mesal notch.

EGG (Figs 13D-F, 14). Length 482-539 $\mu \mathrm{m}$, width 226-232 $\mu \mathrm{m}(\mathrm{N}=5)$. Several mature eggs were dissected from female terminalia. Teardrop-shaped with long, slender collar and petiolate anchor. Anchor mushroom-shaped with marginal rows of globular bodies, pedicle stalked and hidden by anchor plate. Collar elongated and slender, with a short, flanged rim. Chorion dark brown, covered with fine punctuations. Micropylar orifices sessile, much larger than punctuations, set on subequatorial line.

\section{Distribution}

Originally described from Tam Dao, Vietnam, and herein reported from China: Guangdong Province.

\section{Remarks}

The Chinese specimens are similar to the original description of Chinoperla gorohovi from northern Vietnam, in regards of head pattern, male terminalia, aedeagal tube, and the long apical spine of the aedeagal sac. However, the Chinese specimens differ in having two membranous dorsomedial lobes on the aedeagal sac (compare Fig. 12A-B with Sivec \& Stark 2010: fig. 2). In the type specimens, the aedeagal sac apically has only one dorsal membranous lobe. In addition, the aedeagal sac of the Chinese specimens have an obscure, slightly sclerotized ventroapical patch, without a ventroapical spinose lobe, while in the type specimens, the aedeagal sac lacks the sclerotized ventroapical area, but has a short additional ventroapical spinose lobe. Unfortunately, the type specimens are permanently not available for study due to the re-organization of the Slovenian Museum of Natural History, Ljubljana (PMSL) collection (Ignac Sivec pers. com.).

\section{Key to species of Chinoperla (males) known from China}

1. Forewing has a long Sc vein (Fig. 15A) C. nigroflavata (Wu, 1948)

- Forewing has a short Sc vein (Fig. 8C)

2. Median sclerite of tergum 9 is weakly sclerotized or wider basally than apically .......................... 3

- Median sclerite of tergum 9 is well sclerotized, wider apically than basally (Fig. 1C) .................. 4

3. Median sclerite of tergum 9 is an inverted triangle bearing two finger shaped posterolateral projections (Fig. 15B) C. biprojecta Lü, Yan, Li \& Wang, 2019

- Median sclerite of tergum 9 is nail-shaped, terminating in an expanded apex (Fig. 11B-D)

C. gorohovi Sivec \& Stark, 2010

4. Aedeagus apically has a large lobe, and pair of spiny lobes without numerous apical spines (Fig. 15C) C. mengmanensis Qian \& Du, 2012

- Aedeagus has less than three apical lobes and numerous large apical spines 5

5. Aedeagus lacks apical comb-shaped sclerite (Figs 7, 10) C. nigrifrons (Banks, 1939)

- Aedeagus has an apical comb-shaped sclerite C. changjiangensis sp. nov.

\section{Discussion}

In this study, we reviewed six species of Chinese Chinoperla. Species of Chinoperla are known from the Oriental realm, including China, India, Indonesia, Thailand and Vietnam. Within China, the genus is 


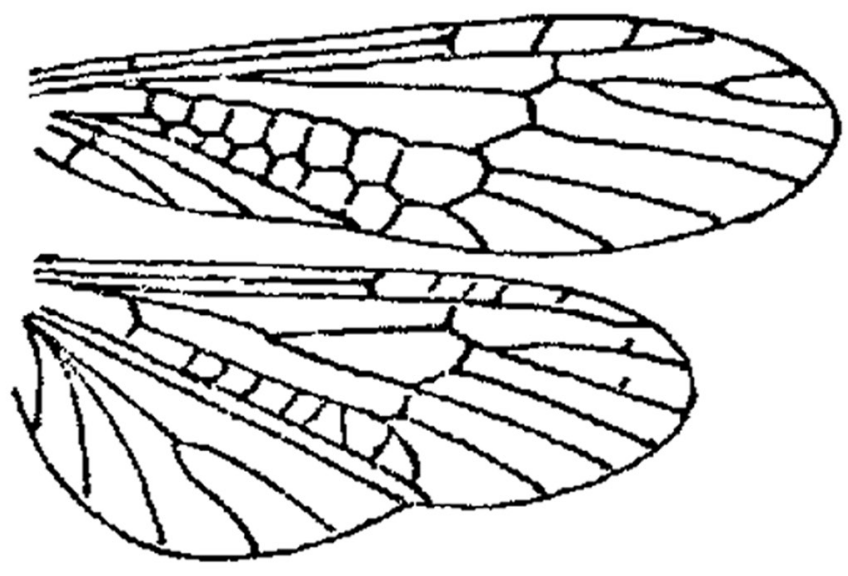

A

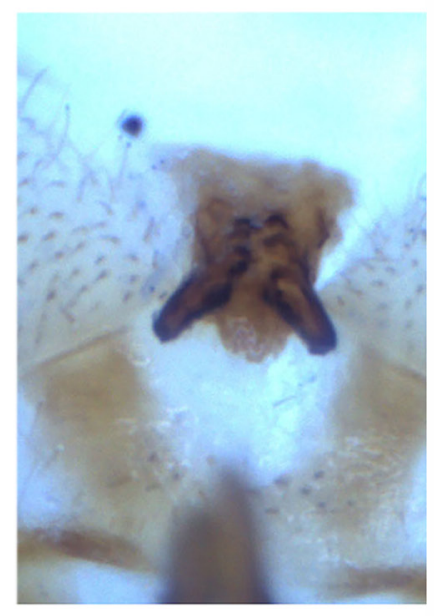

B

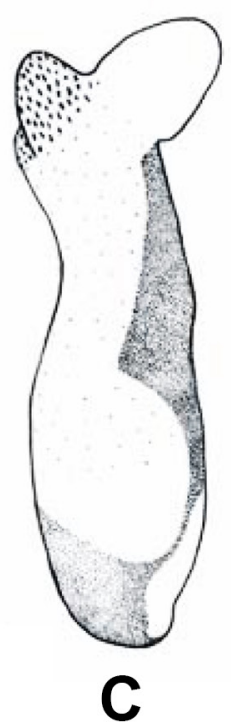

Fig. 15. A. Wings of Chinoperla nigroflavata (Wu, 1948), drawing modified from Wu (1948). B. Median sclerite of tergum 9 of $C$. biprojecta Lü, Yan, Li \& Wang, 2019, dorsal view, illustration from Lü et al. (2019a). C.Aedeagus of C. mengmanensis Qian \& Du, 2012, lateral view, drawing modified from Qian \& $\mathrm{Du}$ (2012). Not to scale.

presently known to be restricted to the south including Fujian, Guangdong, Hainan and Yunnan Provinces. The region is rich in different types of surface waters, dominated by a tropical and subtropical monsoon climate, with high temperature and heavy rain in summer and less rain in mild winter. Due to the similar climate and environmental conditions, more members of the genus are expected in other provinces of the area, such as Guangxi, Guizhou, Hunan, Jiangxi and Zhejiang.

The male terminalia and aedeagus are regarded as the most important morphological characters in the taxonomic study of Chinoperla. As an important part of the male terminalia, the hemitergal processes of the members of the genus are usually slender and tapering to apex. The hemitergal processes of C. nigrifrons (Banks, 1939) are suddenly constricted at the apical half, forming an apical notch in lateral view. The notch is unique in the genus, distinguishing this species from others. The apical part of the aedeagus of species of Chinoperla usually bear lobes and spines, and some species have a ventroapical comb-shaped sclerite. The shape of the basal pattern, and the size and number of apical spines are also important features for identification. The apical lobe of the aedeagus of the genus is large and membranous, bearing or lacking spines, and some species have more than one apical lobe, but this structure has sometimes been overlooked in previous studies. In addition, the head of Chinoperla is often covered by a large dark marking, and a triangular or subtriangular darker spot. The head pattern can be very similar, and its detailed features were often overlooked. The head pattern of C. nigrifrons is heart-shaped with a rounded apex, which is easily distinguishable from those of the congeners. According to the newly described or redescribed species in the present paper, we propose the use of the details of characteristics of the head pattern, apical lobe and spines of aedeagus, and hemitergal processes of tergum 10 in the delimitation of species of Chinoperla.

\section{Acknowledgments}

We would like to thank colleagues at the Museum of Comparative Zoology (MCZ), Harvard University, Cambridge, Massachusetts, and the National Zoological Museum of China, Institute of Zoology, Chinese 
Academy of Sciences, Beijing (IZCAS), for allowing us to study the specimens. This work was supported by National Animal Collection Resource Center, China and China Scholarship Council. We acknowledge the support of our research by the National Natural Science Foundation of China (No. 31970402) and the Program for Science \& Technology Innovation Talents in Universities of Henan Province (No. 21HASTIT042).

\section{References}

Banks N. 1939. New genera and species of neuropteroid insects. Bulletin of the Museum of Comparative Zoology 85: 439-504.

Cao T.K.T. \& Bae Y.J. 2007. Chinoperla rhododendrona, a new species of Perlidae (Insecta: Plecoptera) from Vietnam. Integrative Biosciences 11 (2): 125-128. https://doi.org/10.1080/17386357.2007.9647324

Chen Z.T. \& Du Y.Z. 2018. A checklist and adult key to the Chinese stonefly (Plecoptera) genera. Zootaxa 4375 (1): 59-74. https://doi.org/10.11646/zootaxa.4375.1.2

Chen Z.T. \& Hou J.L. 2020. A new species of Hemacroneuria and additions to Chinoperla (Plecoptera: Perlidae) from China. Zootaxa 4751 (1): 161-171. https://doi.org/10.11646/zootaxa.4751.1.10

DeWalt R.E., Maehr M.D., Hopkins H., Neu-Becker U. \& Stueber G. 2021. Plecoptera Species File Online. Version 5.0/5.0. Available from http://Plecoptera.SpeciesFile.org [accessed 21 Feb. 2021].

Du Y.Z., Sivec I. \& He J.H. 1999. A checklist of Chinese species of the family Perlidae (Plecoptera: Perloidea). Acta Entomologica Slovenica 7 (1): 28-33.

Illies J. 1966. Katalog der rezenten Plecoptera. Das Tierreich, Berlin.

Li W.H., Murányi D. \& Wang R.F. 2014. Species of Neoperla (Plecoptera: Perlidae) from Yunnan Province, China. Zootaxa 3753 (1): 1-9. https://doi.org/10.11646/zootaxa.3753.1.1

Lü D.B., Yan Y.H. \& Li W.H. 2019a. A new species of the genus Chinoperla (Plecoptera: Perlidae) from southern China. Zootaxa 4614 (1): 187-190. https://doi.org/10.11646/zootaxa.4614.1.10

Lü D.B., Yan Y.H. \& Li W.H. 2019b. Erratum: A new species of the genus Chinoperla (Plecoptera: Perlidae) from southern China. Zootaxa, 4614: 187-190. Zootaxa 4658 (3): 600-600.

https://doi.org/10.11646/zootaxa.4658.3.12

Qian Y.H. \& Du Y.Z. 2012. One new species in the genus Chinoperla (Plecoptera: Perloidea). Entomotaxonomia 34 (12): 117-119.

Sivec I. \& Stark B.P. 2010. Five new species of Chinoperla Zwick (Plecoptera: Perlidae) from Vietnam and Thailand. Illiesia 6 (8) 62-74.

Sivec I. \& Zwick P. 1989. Addition to the knowledge of genus Chinoperla (Plecoptera: Perlidae). Aquatic Insects 11 (1): 11-16. https://doi.org/10.1080/01650428909361341

Sivec I., Stark B.P. \& Uchida S. 1988. Synopsis of the world genera of Perlinae (Plecoptera: Perlidae). Scopolia 16: 1-66.

Wang H.L., Wang G.Q. \& Li W.H. 2013. Two new species in the subfamily Perlinae (Plecoptera, Perlidae) from China. ZooKeys 313: 81-90. https://doi.org/10.11646/zootaxa.3872.1.2

Wu C.F. 1948. Fourth supplement to the stoneflies of China (Order Plecoptera). Peking Natural History Bulletin 17: 75-80.

Wu C.F. 1973. New species of Chinese stoneflies (Order Plecoptera). Acta Entomologica Sinica 16: $97-118$. 
MO R.R. et al., Review of Chinoperla (Plecoptera: Perlidae: Perlinae) from China

Yang D. \& Li W.H. 2018. Species Catalogue of China. Vol. 2. Animals, Insecta (III), Plecoptera. Science Press, Beijing.

Zwick P. 1980. Plecoptera (Steinfliegen). Handbuch der Zoologie 4: 1-115.

Zwick P. 1982. Contribution to the knowledge of Chinoperla (Plecoptera: Perlidae: Neoperlini). Aquatic Insects 4 (3): 167-170. https://doi.org/10.1080/01650428209361102

Zwick P. \& Sivec I. 1980. Beiträge zur Kenntnis der Plecoptera des Himalaja. Entomologica Basiliensa 5: 59-138.

Manuscript received: 23 April 2021

Manuscript accepted: 30 August 2021

Published on: 19 October 2021

Topic editor: Nesrine Akkari

Section editor: Helen M. Barber-James

Desk editor: Radka Rosenbaumová

Printed versions of all papers are also deposited in the libraries of the institutes that are members of the EJT consortium: Muséum national d'histoire naturelle, Paris, France; Meise Botanic Garden, Belgium; Royal Museum for Central Africa, Tervuren, Belgium; Royal Belgian Institute of Natural Sciences, Brussels, Belgium; Natural History Museum of Denmark, Copenhagen, Denmark; Naturalis Biodiversity Center, Leiden, the Netherlands; Museo Nacional de Ciencias Naturales-CSIC, Madrid, Spain; Real Jardín Botánico de Madrid CSIC, Spain; Zoological Research Museum Alexander Koenig, Bonn, Germany; National Museum, Prague, Czech Republic. 